\title{
Two Years of Observations of Warm-Core Anticyclones in the Labrador Sea and Their Seasonal Cycle in Heat and Salt Stratification
}

\author{
M. F. DE JONG, A. S. BOWER, AND H. H. Furey \\ Woods Hole Oceanographic Institution, Woods Hole, Massachusetts
}

(Manuscript received 25 March 2013, in final form 1 November 2013)

\begin{abstract}
Between 25 September 2007 and 28 September 2009, a heavily instrumented mooring was deployed in the Labrador Sea, offshore of the location where warm-core, anticyclonic Irminger rings are formed. The 2-year time series offers insight into the vertical and horizontal structure of newly formed Irminger rings and their heat and salt transport into the interior basin. In 2 years, 12 Irminger rings passed by the mooring. Of these, $11 \mathrm{had}$ distinct properties, while 1 anticyclone likely passed the mooring twice. Eddy radii $(11-35 \mathrm{~km})$ were estimated using the dynamic height signal of the anticyclones $(8-18 \mathrm{~cm})$ together with the observed velocities. The anticyclones show a seasonal cycle in core properties when observed $\left(1.9^{\circ} \mathrm{C}\right.$ in temperature and 0.07 in salinity at middepth) that has not been described before. The temperature and salinity are highest in fall and lowest in spring. Cold, fresh caps, suggested to be an important source of freshwater, were seen in spring but were almost nonexistent in fall. The heat and freshwater contributions by the Irminger rings show a large spread (from 12 to $108 \mathrm{MJ} \mathrm{m}^{-2}$ and from -0.5 to $-4.7 \mathrm{~cm}$, respectively) for two reasons. First, the large range of radii leads to large differences in transported volume. Second, the seasonal cycle leads to changes in heat and salt content per unit volume. This implies that estimates of heat and freshwater transport by eddies should take the distribution of eddy properties into account in order to accurately assess their contribution to the restratification.
\end{abstract}

\section{Introduction}

The Labrador Sea, located between southern Greenland and Canada, plays an important part in the North Atlantic subpolar gyre. As an extension of this gyre, the basin has a strong cyclonic boundary current and a weak interior flow (Lavender et al. 2000; Cuny et al. 2002). The upper part of this boundary current enters the Labrador Sea around the southern tip of Greenland as the West Greenland Current (WGC) and exits the Labrador Sea past the Hamilton Bank as the Labrador Current (Fig. 1). The boundary current at the entrance of the Labrador Sea was most recently described by Holliday et al. (2007). They depict a two-layer system, with cold, freshwater flowing along the shelf and shelf break in the upper $200 \mathrm{~m}$ of the water column in the WGC. Warmer, more saline water flows along the continental slope at greater depth in the Irminger Current (IC). The warm, saline water type (potential temperature $\theta=\sim 4.5^{\circ} \mathrm{C}$ and

Corresponding author address: M. F. de Jong, Woods Hole Oceanographic Institution, 266 Woods Hole Road, MS 21, Woods Hole, MA 02543.

E-mail: fdejong@whoi.edu salinity $S=\sim 34.95$; Cuny et al. 2002) is often called Irminger Water after its origin in the Irminger Current. All water associated with the WGC and IC here lies above the $27.7 \mathrm{~kg} \mathrm{~m}^{-3}$ isopycnal (Holliday et al. 2009); below this isopycnal lies the fresher, but colder, Labrador Sea Water (LSW).

The Labrador Sea is best known for the formation of LSW (Lazier 1973; Talley and McCartney 1982). LSW is formed by deep convection in cold winters. The process of deep convection has been studied extensively in the laboratory, in models, and in the field (e.g., Jones and Marshall 1993; Visbeck et al. 1996; Marshall et al. 1998; Marshall and Schott 1999; Lilly et al. 1999). During periods of strong surface buoyancy loss the (already weakly stratified) water column becomes unstable and overturns. In the Labrador Sea the convective mixing creates a dense, homogenized water column over an area up to $300 \mathrm{~km}$ wide along the western side of the basin (Pickart et al. 2002). After convection, as the buoyancy loss weakens or ceases altogether, the column of LSW restratifies and spreads to the nearby basins (Talley and McCartney 1982; Lazier et al. 2002; Yashayaev et al. 2007). This restratification process was originally thought to occur through the baroclinic 


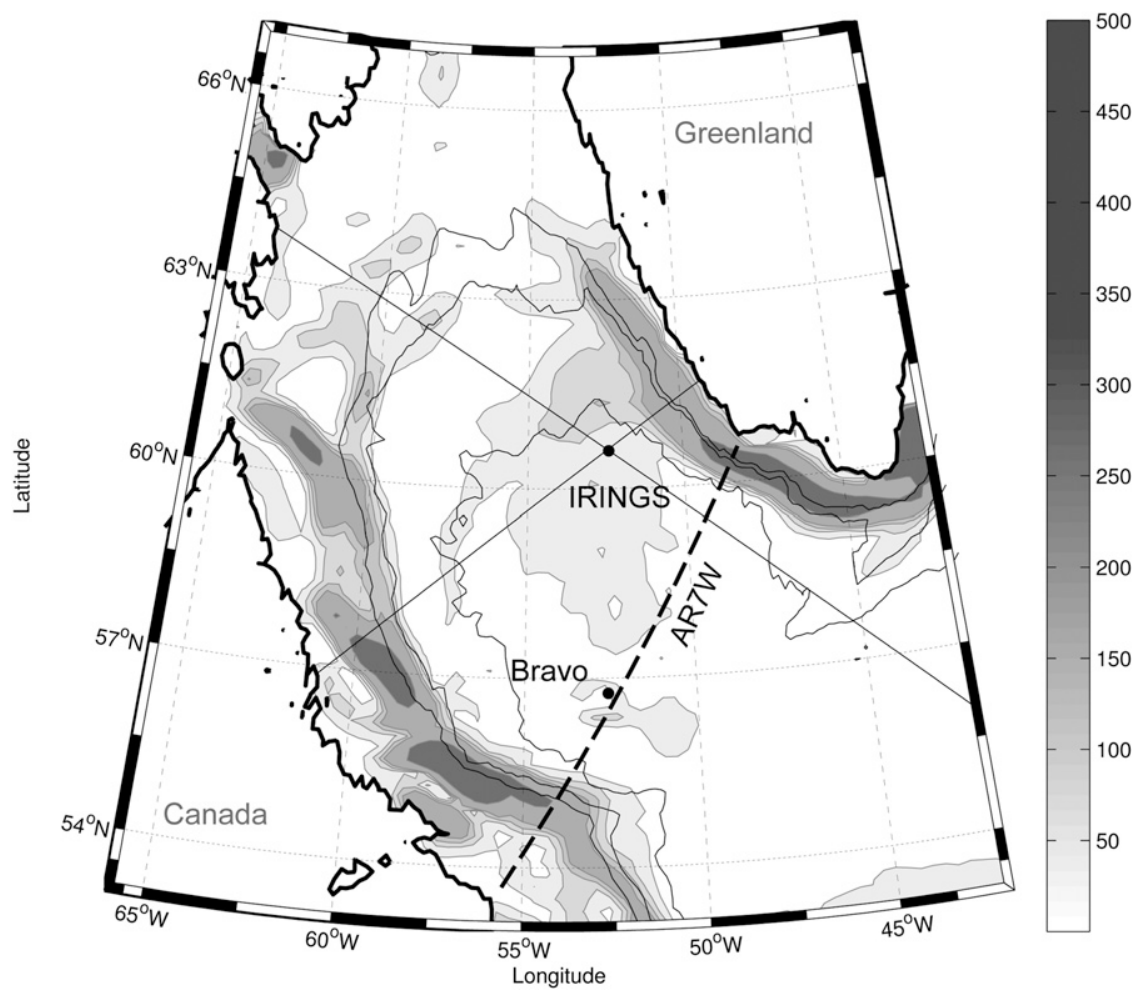

FIG. 1. Map of the Labrador Sea. Shading on this map shows the mean EKE $\left(\mathrm{cm}^{2} \mathrm{~s}^{-2}\right)$ over 2007-09. The WGC and deeper IC flow cyclonically around the basin. Off the coast of west Greenland, the WGC becomes unstable and sheds IRs, which leads to an offshore branching EKE max. Indicated on the map are the locations of the mooring used in this study (IRINGS; short for Irminger rings) and the Bravo mooring as well as the AR7 West (AR7W) section. Two altimetry tracks that cross over the IRINGS mooring location are also shown.

breakup of the convection area (Jones and Marshall 1997; Marshall and Schott 1999). The sharp density front between the convective area and the ambient stratified water becomes baroclinically unstable, breaking up into eddies called convective eddies (CEs). These eddies mix the upper part of the water column while the main body of dense water equilibrates to its density level and spreads along isopycnals. Jones and Marshall (1997) derived a restratification time scale based on CEs in the Labrador Sea of about 100 days.

Mooring time series from the central Labrador Sea showed not only the smaller (from 5- to $18-\mathrm{km}$ radius) cold convective eddies, but also larger $(15-30 \mathrm{~km})$ warmcore eddies (Lilly and Rhines 2002; Lilly et al. 2003). The warm-core eddies were named Irminger rings (IRs), because their core consists of water from the Irminger Current. Because the IRs are much more buoyant, their potential to restratify is larger than that of the CEs. Lilly et al. (2003) describe equal numbers of cold CE and warm IR events observed in the 5-yr time series from the K1 and Bravo moorings (Fig. 1). Model studies show that these Irminger rings are formed in association with the narrowing of the Greenland shelf near Cape Desolation, which renders the WGC/IC baroclinically unstable (Eden and Böning 2002; Bracco and Pedlosky 2003; Wolfe and Cenedese 2006; Bracco et al. 2008). Prater (2002) tracked three eddies from this location at the Greenland shelf using profiling RAFOS floats. The shedding of Irminger rings downstream of Cape Desolation contributes to a maximum in eddy kinetic energy (EKE) near the west Greenland shelf observed in altimetry data (Prater 2002; Lilly et al. 2003; Brandt et al. 2004). The extension of the EKE maximum into the interior basin, combined with the observations of Irminger rings at the Bravo mooring site, suggests that these eddies are long lived enough to reach the convective area in the Labrador Sea, possibly aiding restratification by CEs. Lilly et al. (2003) suggested that the warm-core eddies may make an important contribution to the heat budget of the interior Labrador Sea, but was unable to give an exact estimate due to the uncertainty in the number of Irminger rings formed each year.

Glider observations of three eddies in early 2005 showed that Irminger rings may also contribute to the 


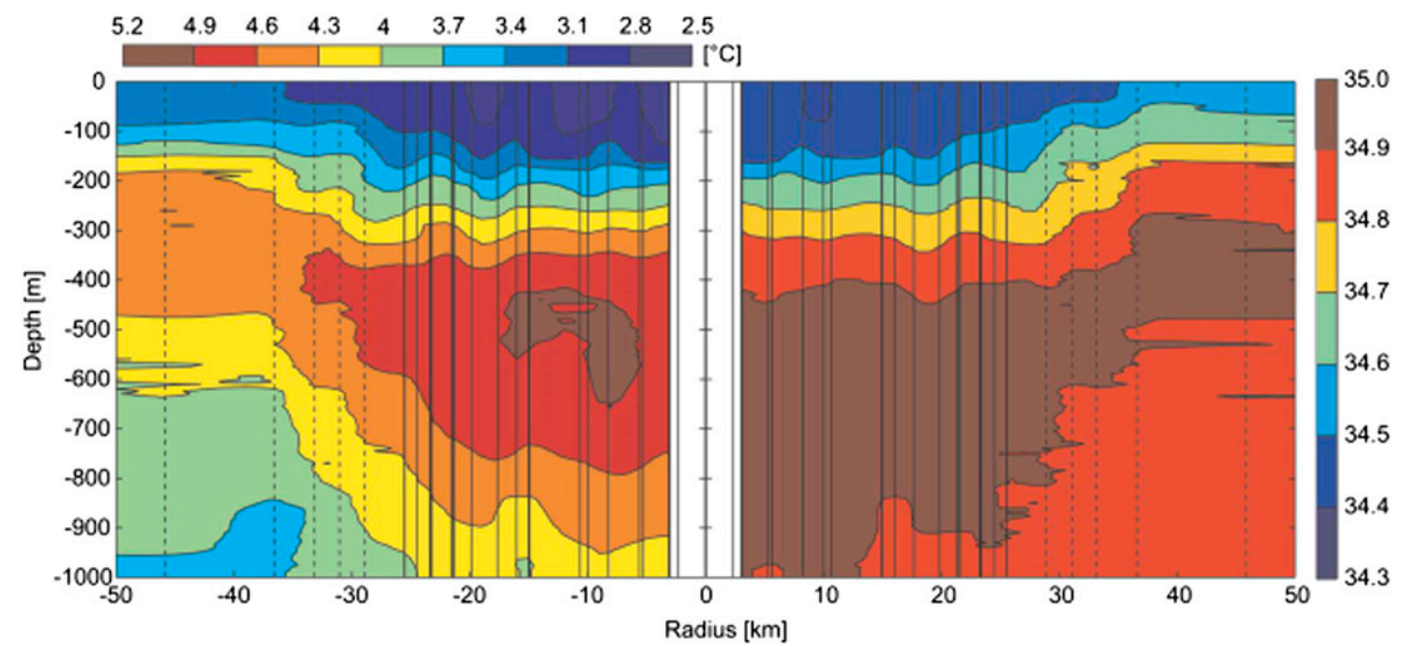

FIG. 2. Reconstruction of the depth radius section of potential (left) temperature and (right) salinity based on glider data [Fig. 11 of Hátún et al. (2007), reproduced with permission]. Solid vertical lines indicate glider dive cycles. The radius of these IRs was estimated to be $21 \mathrm{~km}$.

freshwater flux into the interior Labrador Sea (Hátún et al. 2007). These eddies, which followed the 3000-m isobaths in the northern part of the Labrador Sea, had a 200-m-thick cold, fresh cap on top of the warm core (Fig. 2), a feature that was not seen at the Bravo mooring (Lilly et al. 2003). Hátún et al. (2007) argued that this freshwater likely originated from the upper part of the WGC that is drawn offshore by the eddy. The eddies at the Bravo mooring may have been formed elsewhere (Hátún et al. 2007) or their fresh cap may have been mixed away by convection within the eddies during winter (Lilly et al. 2003). Hátún et al. (2007) offered a revised heat and freshwater budget of the Irminger ring contribution to the restratification of the Labrador Sea, suggesting that it may be up to $50 \%$ of the surface freshwater flux and intermediate heat flux.

Several model studies have since investigated the relative importance of the different types of eddies involved in the restratification process in the Labrador Sea (Katsman et al. 2004; Chanut et al. 2008; Gelderloos et al. 2011). Katsman et al. (2004) concluded that IRs were more important for restratification than the CEs. In the models of Chanut et al. (2008) and Gelderloos et al. (2011), one more eddy type is distinguished: the boundary current eddies (BCEs), formed at the density front between the boundary current and the interior of the Labrador Sea. They are comparable in size to the $\mathrm{CEs}$, are formed year-round, and are formed along the density front of the WGC along the entire boundary of the Labrador Sea. Their formation mechanism, the instability of the boundary current, was investigated by Spall (2004). In the model of Chanut et al. (2008), most IRs followed a northern route between the 2000- and 3000-m isobaths and very few IRs entered the convective area. Therefore, they concluded that the convective area is restratified mostly by CEs and BCEs and that IRs likely enhance the stratification in the northern Labrador Sea, thus restricting the area of deep convection to the southwest. However, in the model of Gelderloos et al. (2011), the IRs did reach the convective area and were responsible for $45 \%$ of the restratification (compared to $25 \%$ for CEs and $5 \%$ for BCEs). The difference between these models may result from different assumptions about forcing and mixed layer depth (Gelderloos et al. 2011).

While models give us a wealth of information about the number of eddies formed each year, they are still idealizations of the real ocean. For example, all three models use temperature as a proxy for density and do not supply information about freshwater transport. Straneo (2006) estimated the lateral fluxes necessary for the restratification by making an inventory of the surface heat and freshwater flux and comparing it with the restratification observed in hydrographic profiles from the Labrador Sea. She arrived at an estimate of about $1 \mathrm{GJ} \mathrm{m}^{-2}$ for the annual heat flux and $0.55 \mathrm{~m}$ of annually added freshwater. Direct studies of warm-core anticyclones have tried to estimate the lateral fluxes by Irminger rings, but these observations are either too far from the formation area (Lilly et al. 2003), still within the northern boundary current (Hátún et al. 2007), or did not sample the eddy core structure (Prater 2002). Therefore, a heavily instrumented mooring was deployed near the EKE maximum, but offshore of the boundary current (Fig. 1). This mooring was meant to observe eddies that do not follow the boundary current, 
but are advected toward the convective region. The instruments on this mooring recorded a 2-year time series of hydrographic and current data. Its location, on a crossover point of two altimetry ground tracks, allows for a comparison of the observed hydrography with sea level anomaly (SLA) data.

In this paper, we present the 2-year time series recorded by the Irminger ring mooring (henceforth called "the mooring" for simplicity) and describe the properties of the warm-core eddies observed by that mooring. The paper is organized as follows: The mooring and data processing are described in section 2 . The time series and the eddy identification method are presented in section 3. In section 4, we compare the mooring observation to altimetry and discuss our method to derive the eddy parameters, such as the radius. The hydrographic properties and the seasonal cycle observed therein are illustrated in section 5. This section also includes an estimate of the resulting heat and salt contribution to the interior Labrador Sea. Section 6 concludes this paper with a discussion of the results.

\section{Data}

The mooring was deployed in the Labrador Sea from 25 September 2007 to 28 September 2009. It was located at $60.6^{\circ} \mathrm{N}$ and $52.4^{\circ} \mathrm{W}$, at a water depth of $3200 \mathrm{~m}$, well offshore of the west Greenland continental shelf and about $430 \mathrm{~km}$ north of the position of the Bravo mooring (Fig. 1). The location of the mooring was chosen such that it would intercept eddies en route to the interior basin, rather than eddies that are advected with the boundary along the northern border of the Labrador Sea. Therefore, it was deployed slightly south of the EKE maximum (Fig. 1). This also guaranteed that passing anticyclones would be completely detached from the boundary current. The mooring (Table 1) was fitted with nine SeaBird Electronics MicroCATs (SBE37), eight Aanderaa recording current meters (RCM11), and two submerged autonomous launch platforms (SALPs; Fratantoni 2013, manuscript submitted to Mar. Technol. Soc. J.). The SALPs were intended to deploy Autonomous Profiling Explorer (APEX) floats in the centers of passing eddies. The float deployment algorithm used by the SALPs and its results are discussed in detail by Furey et al. (2013a). Here, we will focus on the time series recorded by the MicroCATs and current meters. Data return was generally excellent, except that the current meter at $250 \mathrm{~m}$ leaked and failed shortly after deployment. The remaining seven current meters, fitted between 100 and $3000 \mathrm{~m}$, recorded the velocity and temperature every $30 \mathrm{~min}$. The MicroCATs, fitted between 100 and $2000 \mathrm{~m}$, recorded temperature and conductivity every $15 \mathrm{~min}$.
Details about instrument calibration are available in the data report (Furey at al. 2013b). The recorded data were gridded vertically in order to estimate continuous profiles of temperature, salinity, and velocity. A shapepreserving spline function was used to grid the data to 25-dbar intervals. At every time step, this spline fitting was applied to the temperature and salinity at the depths of the MicroCATs. As a control, density profiles were derived both from the newly fitted 25-dbar interval profiles of temperature and salinity as well as by spline fitting the density observations at the original instrument depths (which is necessarily monotonic because of the inherently stable water column). The spline shape parameters were then adjusted to get the best match between the two density profiles. The same spline-fitting function was similarly applied to the $u$ and $v$ velocity measurements.

\section{Mooring time series and eddy recognition}

The 2-year time series of the anomalies of $\theta, S$, and low-pass filtered eastward $u$ and northward $v$ velocity are shown in Fig. 3. The low-pass filtering (40-h Butterworth filter) was applied to the velocities in order to remove the tidal signal. The anomalies were derived by removing the 2-year mean vertical profile from the time series. The timing of the Irminger rings that intersected the mooring are also indicated. The method that was used to detect the Irminger rings will be discussed in the next section. The record of anomalies shows strong variability in temperature and salinity in the upper $1500 \mathrm{~m}$. The lowest-frequency signal seen is the seasonal cycle, with higher temperature (and salinity) in late fall and lower temperature (and salinity) in spring. Superimposed on this low-frequency variability is a fair amount of subtidal variability that is associated with mesoscale structures, as shown later. Potential temperature and salinity covary strongly, which leads to many small anomalies that are more or less density compensating. The Irminger rings show clear negative density anomalies, and their signature of downward displaced isopycnals extends well below their warm core. The records of velocities show that the variability is large with respect to the mean background current, which is under $4 \mathrm{~cm} \mathrm{~s}^{-1}$ at all depths. The variability is likely caused both by passing eddies, some of which may have been too far from the mooring to be recognized as such, and the proximity of the boundary current.

To describe the Irminger rings in this record, their signal first needed to be extracted from the time series. The eddy identification is based on the known characteristics of Irminger rings (Lilly et al. 2003; Hátún et al. 2007). An example of an Irminger ring as described 
TABLE 1. The mooring instrumentation. The mooring contained eight RCM11s, nine SBE37s, and two SALPs to release floats. The observed parameters are eastward velocity (i.e., $u$ ), northward velocity (i.e., $v$ ), temperature (i.e., $T$ ), conductivity (i.e., $C$ ), and pressure (i.e., $p$ ).

\begin{tabular}{cll}
\hline \hline Depth $(\mathrm{m})$ & Instrument type & Parameters/notes \\
\hline 100 & RCM11 & $u, v, T$ \\
101 & SBE37 & $P, C, T$ \\
200 & SBE37 & $C, T$ \\
250 & RCM11 & Instrument failed. \\
400 & SBE37 & $C, T$ \\
500 & RCM11 & $u, v, T$ \\
511 & SALP master & $P, T$ \\
518 & SALP slave & $P, T$ \\
750 & SBE37 & $P, C, T$ \\
1000 & RCM11 & $u, v, T$ \\
1001 & SBE37 & $C, T$ \\
1250 & SBE37 & $C, T$ \\
1500 & RCM11 & $u, v, T$ \\
1501 & SBE37 & $C, T$ \\
1750 & SBE37 & $C, T$ \\
2000 & RCM11 & $u, v, T$ \\
2001 & SBE37 & $C, T$ \\
2500 & RCM11 & $u, v, T$ \\
3000 & RCM11 & $u, v, T$ \\
\hline
\end{tabular}

by Hátún et al. (2007) was shown in Fig. 2. It is an anticyclonic eddy with a warm, saline core and a cold, fresh cap in the upper $200 \mathrm{~m}$. The warm core is centered at approximately 500-m depth, while the high salinity core extends somewhat deeper. The radius of an eddy is defined as the distance between the eddy center and the velocity maximum. The radius of the eddy in Fig. 2 was estimated to be $21 \mathrm{~km}$, with a surface-intensified velocity maximum of $0.5 \mathrm{~m} \mathrm{~s}^{-1}$. These are the structures we want to extract from the mooring time series.

As the automatic detection of eddies in the time series was shown to be of limited success (Furey et al. 2013a), a manual scan of the time series was performed to isolate the eddy events. With the manual scan, we select events that resemble Irminger rings. These events have a positive temperature and salinity anomaly at middepth that results in a downward displacement of the isopycnals as well as a rotation of the currents around the center of the hydrographic anomaly. The timing of the velocity maxima aligns with the extremes in the rate of change in the isopycnal, and the velocity minimum appears during the maximum downward displacement of the isopycnals. The $27.7 \mathrm{~kg} \mathrm{~m}^{-3}$ isopycnal was used as a reference here because it encompassed the waters of the WGC and IC (Holliday et al. 2009). Unlike a glider, which can be steered toward the core of an eddy, a mooring relies on chance encounters. Therefore, the criteria described above require the eddy core to intersect with the mooring so that the velocity maxima and the warm, saline core are observed. At large distances ( $r>R$, with $R$ as the eddy radius), there is no velocity minimum observed during the time of maximum displacement of the isopycnal, and the properties associated with the anticyclones will become too weak altogether to distinguish them from the unsteady background.

In the 2-year time series, 12 warm-core anticyclones, of which the core intersected the mooring, were observed (Table 2; Fig. 3). These anticyclones were predominantly observed during late spring, summer, and fall. Figure 4 shows some examples of the identified anticyclones, a spring eddy, a fall eddy, and one eddy that, unlike all other eddies, showed bottom-intensified velocities. Two features classified as eddies skimming the mooring were seen in late January and early February 2009. Because the mooring did not sample the cores of these eddies their details are not discussed here.

\section{Deriving eddy parameters from the time series}

While plots like Fig. 4 clearly illustrate the vertical structure of the Irminger rings, their rendition of the horizontal structure could be somewhat deceptive, because the horizontal axis is still in units of time and not space. To fully describe the Irminger ring field at the mooring, we need to know the direction in which they traveled, their radius, and their distance from the mooring as they passed by (Fig. 5). These will be determined in a series of steps using a model of an idealized eddy.

The model of choice is that of the Rankine eddy. This model eddy has a core in solid body rotation, and it is often used to describe ocean eddies (Lilly and Rhines 2002). The azimuthal velocity of the Rankine eddy is defined as

$$
\begin{aligned}
& v_{\theta}(r)=V_{\max } \frac{r}{R} \quad \text { for } \quad r<R \quad \text { and } \\
& v_{\theta}(r)=V_{\max } \frac{R}{r} \quad \text { for } \quad r>R,
\end{aligned}
$$

where $V_{\max }$ is the maximum azimuthal velocity found at a distance from the core $r$ equal to the eddy radius $R$. The term $V_{\max }$ is of negative sign for an anticyclone. Additional to $V_{\max }, r$, and $R$, the observed velocities along the mooring track will depend on the direction of travel (i.e., $\alpha$ ) and the minimum distance (i.e., $y$, which is normalized by $R$ ) between the core of the eddy and the mooring. Some examples are shown in Fig. 5. We will attempt to find the values for these parameters next.

\section{a. Direction of propagation}

Determining the direction of travel of an anticyclone in a weak background flow observed in the mooring time 

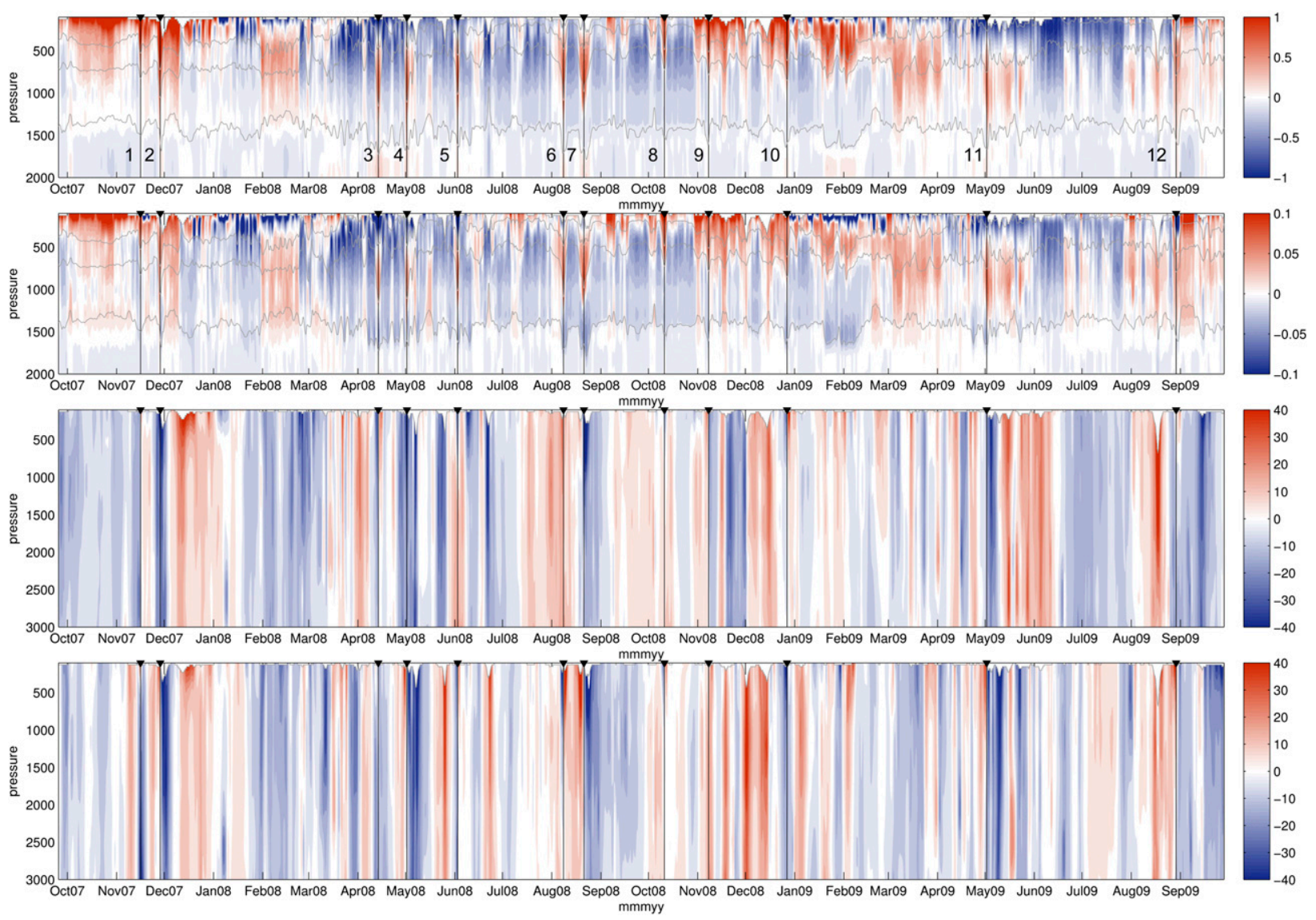

FIG. 3. Time series of anomalies of (from top to bottom) $\theta, S, u$, and $v$. Anomalies were derived by removing the 2-year mean profiles Isopycnals $\left(27.65,27.7\right.$, and $\left.27.75 \mathrm{~kg} \mathrm{~m}^{-3}\right)$ are drawn with gray lines on the upper two panels. Timing of passing eddies are indicated by the vertical lines. The eddy characteristics are warm, saline anomalies with a depression of the isopycnal as well as surface-intensified rotating velocities.

series is quite straightforward. Consider the following conceptual argument: if an anticyclone travels in a westward (northward) direction past the mooring, the velocity will first exhibit a northward (eastward) directed maximum, then decrease to near zero before showing a southward (westward) directed velocity maximum (example 1; Fig. 5, bottom). The opposite is true for an anticyclone that travels eastward (southward). The travel direction can be determined quantitatively by rotating the frame of reference of $u$ and $v$ until a best fit with

TABLE 2. Eddy parameters. The time between the max velocity $\Delta t$, direction of propagation $\alpha$, the max velocity $V_{\max }$, the dynamic height anomaly $D$, the propagation speed $U_{\text {prop }} \pm 1 / 2\left(U_{\text {prop }}^{\text {upper }}-U_{\text {prop }}^{\text {lower }}\right)$, the apparent radius $R_{0} \pm 1 / 2\left[R_{0}\left(U_{\text {prop }}^{\text {upper }}\right)-R_{0}\left(U_{\text {prop }}^{\text {lower }}\right)\right]$, and the geostrophic sea level height anomaly $D_{g}$ derived from $V_{\max }$ and $R_{0} \pm 1 / 2\left[D_{g}\left(U_{\text {prop }}^{\text {upper }}\right)-D_{g}\left(U_{\text {prop }}^{\text {lower }}\right)\right]$.

\begin{tabular}{|c|c|c|c|c|c|c|c|}
\hline Eddy (No.) & $\Delta t(\mathrm{~h})$ & $\alpha$ & $V_{\max }\left(\mathrm{cm} \mathrm{s}^{-1}\right)$ & $D(\mathrm{~cm})$ & $U_{\text {prop }}\left(\mathrm{cm} \mathrm{s}^{-1}\right)$ & $R_{0}(\mathrm{~km})$ & $D_{g}(\mathrm{~cm})$ \\
\hline 1 & 42.5 & $189^{\circ}$ & 13.9 & 9.6 & $41.6 \pm 7.6$ & $31.8 \pm 5.8$ & $8.5 \pm 1.5$ \\
\hline 2 & 71.0 & $251^{\circ}$ & 34.6 & 17.9 & $25.9 \pm 2.4$ & $33.2 \pm 3.0$ & $22.1 \pm 2.0$ \\
\hline 3 & 65.5 & $188^{\circ}$ & 30.7 & 13.7 & $29.7 \pm 1.8$ & $35.0 \pm 2.1$ & $20.7 \pm 1.2$ \\
\hline 4 & 72.0 & $252^{\circ}$ & 40.8 & 14.7 & $14.5 \pm 3.2$ & $18.8 \pm 4.2$ & $14.8 \pm 3.3$ \\
\hline 5 & 40.0 & $102^{\circ}$ & 38.9 & 12.8 & $29.6 \pm 10.6$ & $21.3 \pm 7.6$ & $16.0 \pm 5.7$ \\
\hline 6 & 52.0 & $78^{\circ}$ & 50.2 & 13.6 & $11.7 \pm 1.4$ & $10.9 \pm 1.3$ & $10.6 \pm 1.3$ \\
\hline 7 & 127.5 & $293^{\circ}$ & 42.5 & 12.4 & $8.6 \pm 4.2$ & $19.8 \pm 9.6$ & $16.2 \pm 7.9$ \\
\hline 8 & 43.0 & $103^{\circ}$ & 21.6 & 8.1 & $25.8 \pm 6.6$ & $20.0 \pm 5.1$ & $8.3 \pm 2.1$ \\
\hline 9 & 36.5 & $12^{\circ}$ & 24.6 & 8.2 & $19.7 \pm 0.3$ & $12.9 \pm 0.2$ & $6.1 \pm 0.1$ \\
\hline 10 & 44.5 & $155^{\circ}$ & 47.7 & 12.1 & $14.3 \pm 8.2$ & $11.4 \pm 6.5$ & $10.5 \pm 6.0$ \\
\hline 11 & 53.5 & $294^{\circ}$ & 43.6 & 8.5 & $13.9 \pm 1.7$ & $13.3 \pm 1.6$ & $11.2 \pm 1.3$ \\
\hline 12 & 102.5 & $241^{\circ}$ & 35.1 & 13.1 & $14.1 \pm 0.6$ & $26.1 \pm 1.2$ & $17.6 \pm 0.8$ \\
\hline Mean & 62.5 & & 35.4 & 12.0 & $20.8 \pm 4.0$ & $21.2 \pm 4.0$ & $13.6 \pm 2.8$ \\
\hline
\end{tabular}



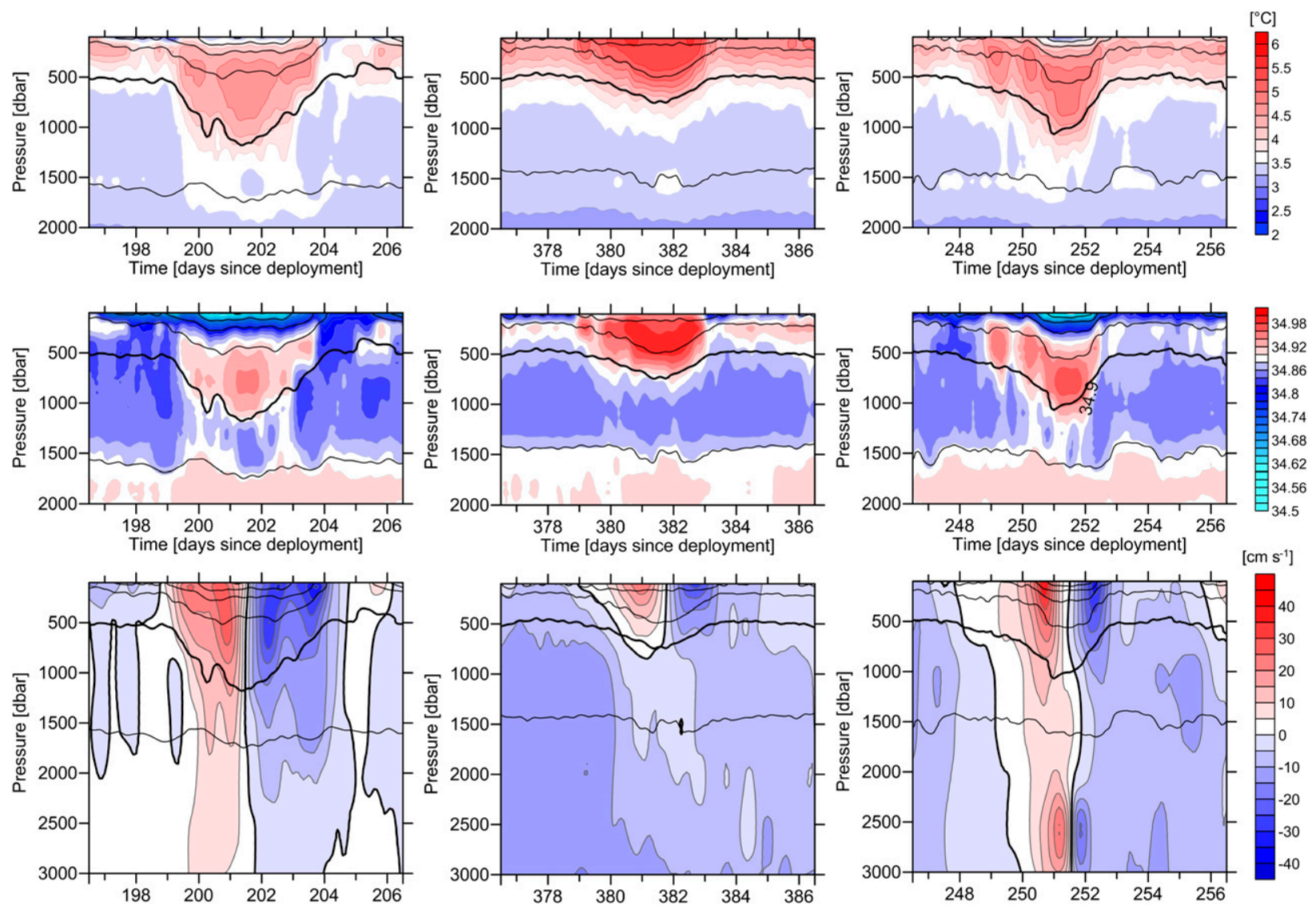

FIG. 4. Examples of passing Irminger rings in the mooring time series. Shown are the potential (top) temperature, (middle) salinity, and (bottom) cross velocity. Isopycnals are drawn every $0.05 \mathrm{~kg} \mathrm{~m}^{-3}$ in black, with the $27.7 \mathrm{~kg} \mathrm{~m}^{-3}$ isopycnal indicated by the thick black line. Spring eddy (eddy 3) with a thick freshwater cap (left). Fall eddy (eddy 8) with a warm, saline upper layer (middle). The only eddy observed to have bottom-intensified velocities (eddy 5 ; right).

a Rankine eddy profile is found. This method assumes that, at a distance from the core $y=0$, all velocities associated with the anticyclone are contained in the direction perpendicular to the mooring track (the cross velocity), while the velocities directed along the mooring track (the along velocity) are zero. If the eddy is advected by a constant background velocity, then per definition this velocity will be in the along direction.

We select a section of time series around each identified eddy of the size of $3 R_{0}$, where $R_{0}$ is the apparent eddy radius or one-half of the distance between the two velocity maxima observed by the mooring. The strongest eddy signature in the velocities is found between $\pm 3 R_{0}$ (Fig. 5); outside of that the eddy signal is weaker and mixed with other signals in the time series. Because the velocities are surface intensified, and the uppermost observations are occasionally interrupted by mooring blowdown, we will use the velocity averaged over the upper $400 \mathrm{~m}$ here. The reference frame for $u$ and $v$ is rotated in order to find the best correlation of $v$ with the zero-order guess, Rankine eddy velocity time series $V_{k}$, which assumes that $y=0, R=R_{0}$, and that the maximum velocity $V_{\max }$ is the mean amplitude of the two velocity peaks. Note that here $R_{0}$ is still measured in time steps because the propagation velocity is unknown. The rotation angle $\alpha$, at which the correlation between $v$ and $V_{k}$ is strongest, is the direction of travel. The results for $\alpha$ are denoted in Table 2. Three of the anticyclones are observed to move eastward, back toward the boundary current. Also, several of the APEX floats deployed by the mooring in this study were in fact entrained into the boundary current. This is likely a result of the mooring location, which was on the boundary of the low pressure area off the coast of west Greenland. The recirculation associated with this low pressure area was identified by Lavender et al. (2000).

\section{b. Comparing mooring observations with altimetry}

The mooring was deployed on a crossover point of altimetry ground tracks with the intention of using the altimetry data to estimate eddy parameters. Both gridded altimetry data [the delayed time reference global-merged 

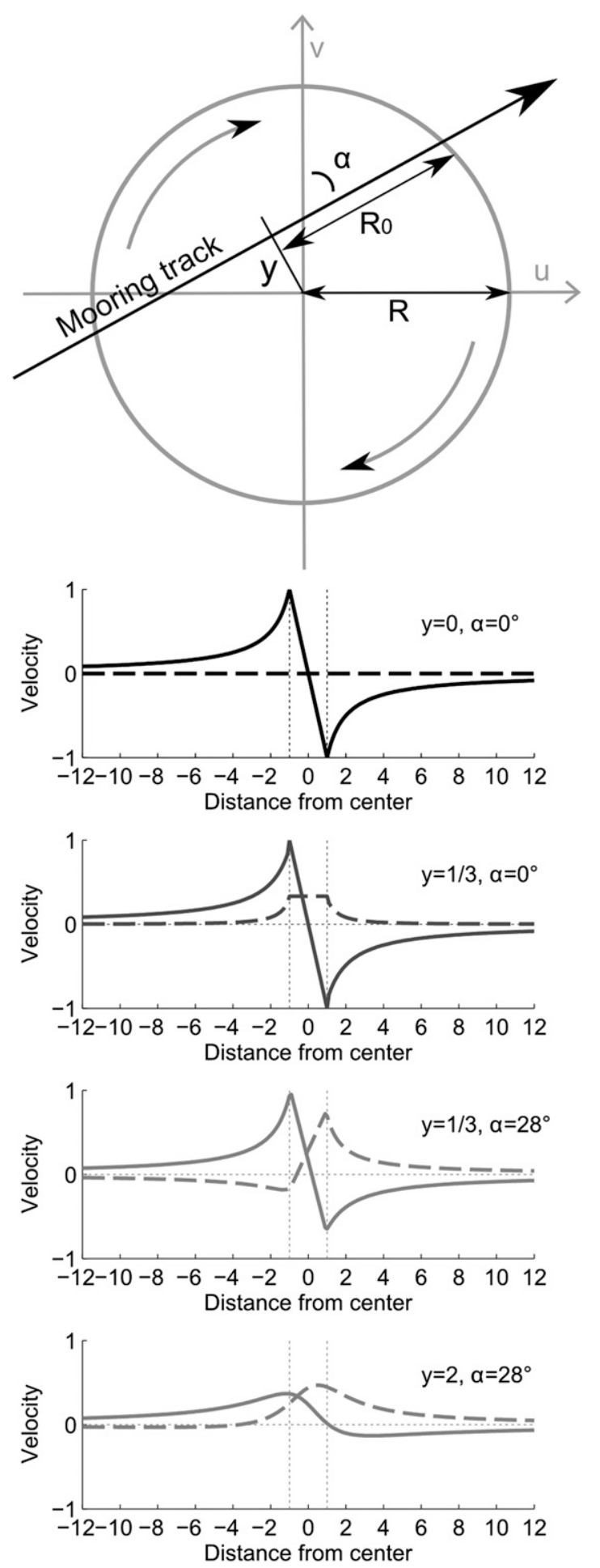

FIG. 5. (top) Eddy parameters in the frame of reference of the eddy. The circle indicates the max velocity of the eddy at $R$. The mooring track through the eddy has an angle $\alpha$ relative to the north. The min distance at which the center of the eddy passed the mooring is $y$. The observed radius between the center and the max velocity is $R_{0}$, with $R_{0}<R$. (bottom) Several examples for the $u$ (dashed) and $v$ (solid) velocities at different $\alpha$ and $y$. maps of SLA from the Archiving, Validation, and Interpretation of Satellite Oceanographic data (AVISO)] and along-track data [the merged Ocean Topography Experiment (TOPEX)-Jason Ocean Surface Topography Mission (OSTM), version 1.1, along-track data from the Physical Oceanography Distributed Active Archive Center (PO.DAAC)] were downloaded for comparison with the mooring data. SLA maps and tracks at and near the time that an eddy was detected in the mooring time series were analyzed.

Ideally, the altimetry data can be used to estimate the eddy radius and/or the propagation velocity. However, as mentioned by Chelton et al. (2011), the method employed by AVISO to create the smooth-gridded SLA maps filters out features with spatial scales smaller than $40 \mathrm{~km}$. This strongly reduces the amplitude of the sea level anomaly of the relatively small eddies in the Labrador Sea. In fact, we were not able to consistently track eddies observed by the mooring in the AVISO-gridded SLA maps. The closest of the anticyclone tracks in the Labrador Sea, identified by Chelton et al. (2011; http:// cioss.coas.oregonstate.edu/eddies/), passed at a distance of $16 \mathrm{~km}$ from the mooring, but did not correspond to an eddy observed in the mooring time series. Their inferred estimates of its radius, amplitude, and radial velocity $\left(60 \mathrm{~km}, 5 \mathrm{~cm}\right.$, and $\left.10 \mathrm{~cm} \mathrm{~s}^{-1}\right)$ are quite atypical for observations of (anti)cyclones in the Labrador Sea and illustrate the heavy smoothing applied to the gridded maps.

The along-track altimetry, with its 7-km resolution, is not filtered and therefore offers more possibilities to track small-scale sea surface height anomalies. Prater (2002) compared the along-track altimetry to the estimated sea surface height anomaly of anticyclones in the Labrador Sea, although only one satellite ground track repeat sampled an eddy tracked by Prater's floats. On only one occasion did the observations along an altimetry track coincide with the presence of an eddy at our mooring. The second eddy in our time series was observed to pass by the mooring between 26 November and 2 December 2007. The southwest-northeast (SW$\mathrm{NE})$ directed altimetry track over the mooring location was observed on 28 November 2007, near the time that the eddy center was observed at the mooring. The northwest-southeast (NW-SE) directed track was observed two days later when the isopycnal displacement at the mooring had returned to nearly zero. Therefore, this track did not sample the core of the eddy. The SLA derived from the SW-NE directed altimetry track is shown in Fig. 6. The SLA was filtered with a 5-point Hamming filter in order to reduce noise.

It is interesting to compare the SLA section observed over eddy 2 with the dynamic height derived from the 

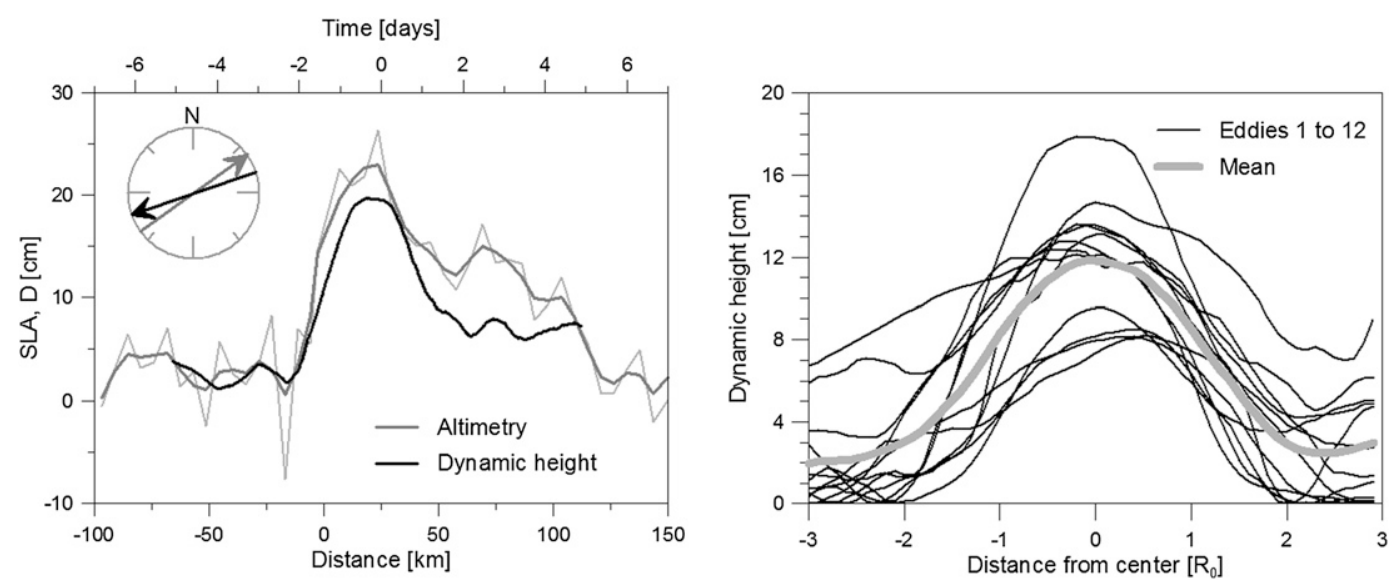

FIG. 6. (left) SLA from along-track data as a function of distance from the mooring (negative values are to the SW of the mooring) across eddy 2 . Unfiltered SLA and velocity data are drawn in light gray and data filtered with a 5-point Hamming filter are drawn in dark gray. The dynamic height derived from the mooring hydrography as a function of time for eddy 2 is shown by a black line. The direction of propagation of the eddy (black) and the direction in which the altimetry track was observed (gray) are illustrated in the inset. Both methods observed the SW corner of the eddy first. (right) Dynamic height signals of all 12 warm-core anticyclones. The dynamic height signal between $-3 R_{0}$ and $+3 R_{0}$ of each of the 12 anticyclones is plotted in the left panel (thin lines). Because the dynamic height around the anticyclones was often asymmetric, the mean (thick line) does not drop off to zero at the sides.

hydrography observed by the mooring (Fig. 6). The dynamic height $D$ is

$$
D\left(p_{1}, p_{2}\right)=\int_{p_{2}}^{p_{1}} \delta(T, S, p) d p
$$

where $p_{1}$ and $p_{2}$ are two reference pressure levels, $\delta$ is the specific volume anomaly, $T$ is the temperature, $S$ is the salinity, and $p$ is the pressure. Here we use the top and bottom of the hydrographic observations of the mooring, 100 and $2000 \mathrm{dbar}$, respectively, as reference pressure levels. During the blowdown event, the upper, missing observations are filled in using the uppermostobserved $T$ and $S$, assuming a constant profile. The dynamic height of eddy 2 as a function of time is shown in Fig. 6 (left) together with the filtered altimetry section of eddy 2 . The two profiles are very similar, also due to the small difference $\left(17^{\circ}\right)$ in the angle of the altimetry track and the eddy propagation derived from the rotation [inset in Fig. 6 (left)].

\section{c. Deriving the apparent eddy radius from dynamic height}

The good correlation between the dynamic height and SLA of eddy 2 encouraged us to estimate the radii of the eddies using their dynamic height time series. The dynamic height anomaly time series of the 12 eddies (and their mean) is shown in the right panel of Fig. 6. The anomalies range between 8 and $18 \mathrm{~cm}$, with a mean of $12 \mathrm{~cm}$ (Table 2). The dynamic height signature of eddy 2 , which coincided with an altimetry track observation [Fig. 6 (left)], was in fact the largest dynamic height anomaly of the 2-year series.

We assume here that the dynamic height is a good substitute for the sea level height we would have gotten from the altimetry tracks if they had sampled the eddies. The eddy cross velocities can be estimated from sea level height gradients by

$$
v_{c}=\frac{g}{f} \frac{d \eta}{d x}
$$

where $v_{c}$ is cross velocity, $f$ is the Coriolis parameter, $g$ is the gravitational acceleration, and $d \eta / d x$ is the lateral gradient of the sea level anomaly associated with the eddy (Lilly et al. 2003). The geostrophic balance is appropriate because the Rossby number Ro is small $(\mathrm{Ro}=V / f L=0.1$ for $\left.V=0.35 \mathrm{~m} \mathrm{~s}^{-1} ; L=20 \mathrm{~km}\right)$. We assume that $\eta \approx D$, the dynamic height. Because we have no spatial information from the mooring, we must approximate $d x$ by $U_{\text {prop }} d t$, where $U_{\text {prop }}$ is the propagation velocity of the eddy past the mooring. That leaves us with the approximation

$$
v_{c} \approx \frac{g}{f} \frac{d D}{U_{\text {prop }} d t}
$$

A 12-h running mean filter is applied to the dynamic height to reduce the spikiness in the gradient $d D / d t$. We fit $U_{\text {prop }}$ to match the left- and right-hand sides of Eq. (5) 

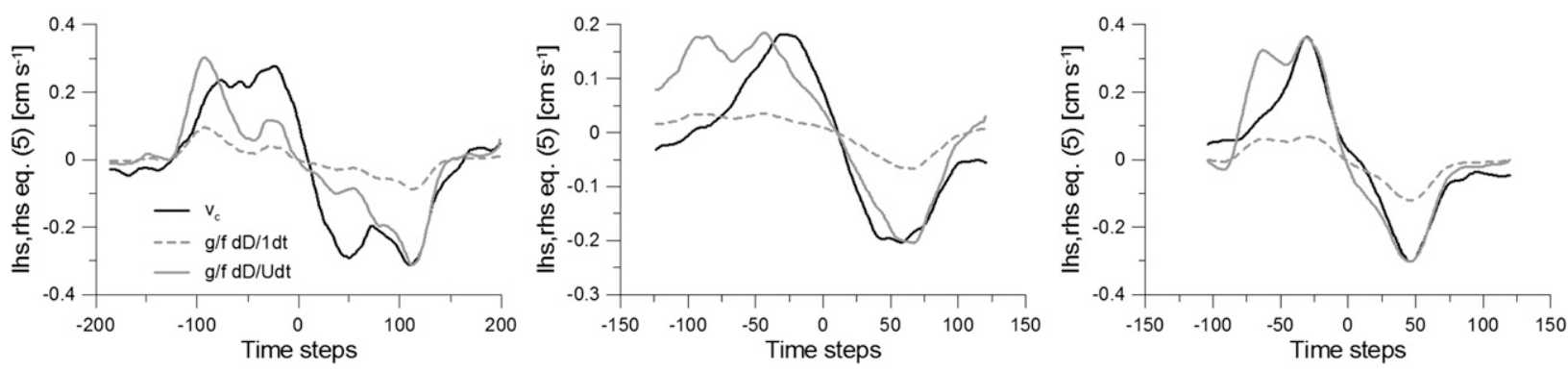

FIG. 7. Estimating the propagation velocity $U_{\text {prop }}$ using Eq. (5). Three examples are shown that correlate to the three eddies in Fig. 4: eddies (left) 3, (middle) 8 , and (right) 5 . The $U_{\text {prop }}$ is estimated by fitting the peaks in the dynamic height gradient (dashed gray) to the peaks in the cross velocity $v_{c}$ (black). The $U_{\text {prop }}$ is determined separately for the leading and trailing peaks and is assumed to vary linearly between the two peaks in $v_{c}$. The resulting velocity after adjustment of $U_{\text {prop }}$ [rhs of Eq. (5)] is represented by the gray solid lines.

at both extremes of the dynamic height gradient. In between, we assume that $U_{\text {prop }}$ varies linearly. Some examples are shown in Fig. 7. Fitting both extremes separately gives us a mean $U_{\text {prop }}$ (the mean between the two fitted velocities) as well as a measure of the asymmetry resulting in an upper and lower bound for $U_{\text {prop. }}$.

With $U_{\text {prop }}$, we can estimate the apparent radius $R_{0}$. The $R_{0}$ and $U_{\text {prop }}$ for all 12 eddies are summarized in Table 2 . The uncertainty in $R_{0}$, defined here as one-half of the difference between $R_{0}\left(U_{\text {prop }}^{\text {upper }}\right)$ and $R_{0}\left(U_{\text {prop }}^{\text {lower }}\right)$, is also denoted there. The range of apparent radii is 11$35 \mathrm{~km}$. The expected sea level height anomaly $\eta_{e}$, derived by solving Eq. (4) for $\eta$ using Eqs. (1) and (2) and assuming that $\eta \rightarrow 0$ in the far field, gives an indication of the reliability of our estimate of $R_{0}$.

We find that, although our estimates of $R_{0}$ have a significant uncertainty, the range of sizes is quite robust. The correlation between the observed dynamic height anomaly of the eddies and $\eta_{e}$ is 0.7 . This is significantly better than a zero-order guess of $\eta_{e}$, assuming all $R_{0}$ are equal to the mean $(21 \mathrm{~km})$, which leads to a correlation between $D$ and $\eta_{e}$ of 0.2. Even so, the range of propagation velocities associated with the radii in Table 2 is large, $8.6-41.6 \mathrm{~cm} \mathrm{~s}^{-1}$. This upper limit of $U_{\text {prop }}$ is rather high, which can be caused by two reasons. This high $U_{\text {prop }}$ was derived for eddy 1 , which had the weakest isopycnals displacement, and our method may not be suitable for this eddy. Also, the high $U_{\text {prop }}$ may suggest that the eddies are not merely translating as a result of the background flow, but are translating as a result of eddyeddy interaction (Lilly et al. 2003).

\section{d. Distance from the eddy core and precision on radius estimates}

To get a better estimate of the actual radius we need to know the distance from the mooring to the eddy core (Fig. 5). We examined the direction of the velocities at the velocity maximum as a way to estimate the distance from the center. This method assumes that the eddy is circular and that at $y=0$ the velocity at $-R_{0}$ is purely northward and at $R_{0}$ is purely southward (Fig. 8). At $y=R$, the velocity will be directed purely in the zonal direction (with the sign depending on the position of the eddy core relative to the mooring). Because the deviations from north and south were small (on average $19^{\circ} \pm 10^{\circ}$ ), the distances from the core were on average $0.3 R_{0}$ and likely no larger than $0.6 R_{0}$, which translates to a mean correction of $4 \%$ (through $R=\sqrt{R_{0}^{2}+y^{2}}$ ) and a maximum correction on the radius of $17 \%$. Furthermore, we have selected only eddies that had two distinct velocity maxima. At a distance of $y=3 / 4 R$, the two velocity maxima observed along the mooring track through the eddy merge into one and any eddy in our record would be classified as a skimming eddy. This gives us an absolute maximum error (for $y=3 / 4 R$ ) on the radius of $25 \%$ or a correction of $2.9 \mathrm{~km}$ for the smallest eddy $\left(R_{0}=11.4 \mathrm{~km}\right)$ and $8.8 \mathrm{~km}$ for the largest eddy $\left(R_{0}=35.0 \mathrm{~km}\right)$. Given the mostly smaller angles observed and the relative large uncertainties already derived from the two estimates of the propagation velocity, we do not make any further corrections on $R$ and assume that $R=R_{0}$ with the uncertainties given in Table 2.

\section{Hydrographic properties}

\section{a. Core properties and their seasonal cycle}

The average potential temperature of the warm core, as observed by the instruments, is $5.3^{\circ} \mathrm{C}$. The range of temperatures is $4.7^{\circ}-6.6^{\circ} \mathrm{C}$ (Table 3 ), with core temperatures following a seesaw-shaped seasonal cycle. The hydrographic characteristics of most of the anticyclones are sufficiently distinct to assume that they are not the same feature observed twice. An exception is made for events 6 and 7, which occurred about 10 days apart in August 2008. These two events show enough similarity 

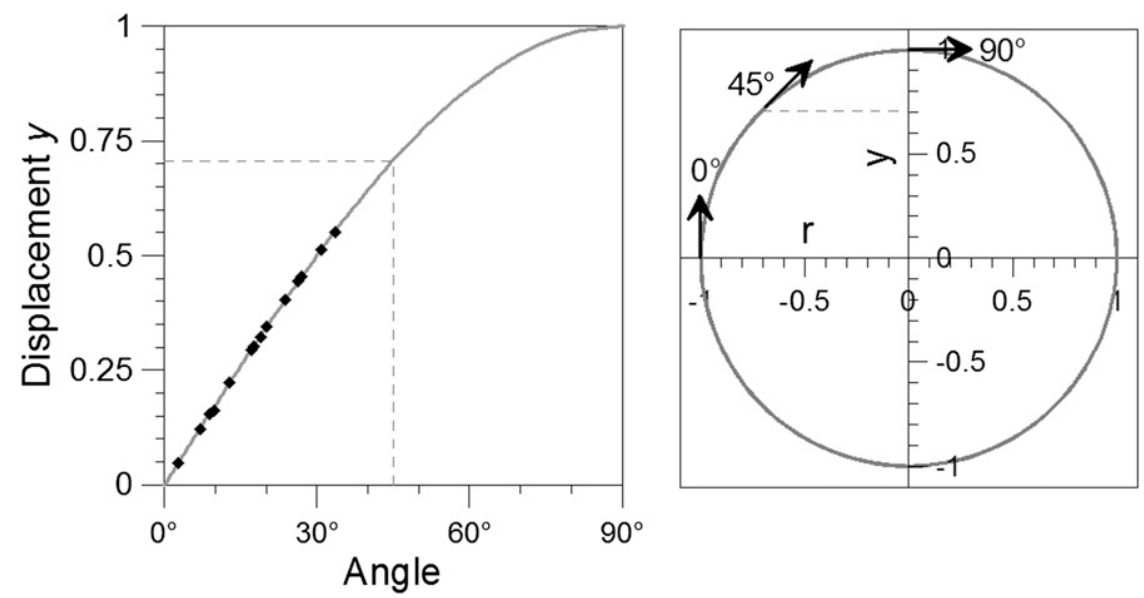

FIG. 8. (left) The angle (relative to north) of the radial eddy velocity at the eddy circumference $r=R$ as a function of the distance from the core $y$ (gray line). (right) At $y=0$ (and $\alpha=0$ ) the radial velocity is purely in the $v$ (north-south) direction (see Fig. 5). At $y=R$, the radial velocity is purely in the $u$ (east-west) direction. The black symbols (left) show the angle relative to the north (south) of the observed velocity of each eddy at the max velocity at $-R_{0}\left(R_{0}\right)$.

(Tables 2 and 3) that we cannot exclude the possibility that we sampled the same feature twice.

The vertical stratification in the centers of the anticyclones is illustrated by Fig. 9. These profiles show a clear seasonal cycle and are therefore organized by their month of observation: winter [January-March (JFM; blue lines, no eddies)], spring [April-June (AMJ; green lines, 4 eddies)], summer [July-September (JAS; orange lines, 3 eddies)], and fall [October-December (OND; dark red lines, 5 eddies)]. The seasonal-mean profiles are also shown. In spring, the anticyclones have a deep, weakly stratified, warm, and saline core extending between 400 and $1200 \mathrm{~m}$, while the layer above $400 \mathrm{~m}$ is the coldest and has the lowest salinity. In summer, the upper part of the water column warms and becomes more saline; this is seen both in the seasonal-mean profiles and in the eddy profiles. In fall, the warm saline cores are seen to extend between 800 and our uppermost instrument at $100 \mathrm{~m}$. Salinities still tend to decrease toward the surface, but the reversal in temperature stratification disappears or is limited to a very shallow layer. The seasonal cycle in stratification will have an impact on the heat and freshwater contributions of the anticyclones, as we will show next.

\section{b. Heat and freshwater contribution to the interior Labrador Sea}

Following Hátún et al. (2007), we calculate the heat and salt contribution of the anticyclones to a recently convected Labrador Sea. Hátún et al. (2007) assume a larger radius $r_{e}$ of $35 \mathrm{~km}$ for this calculation because the heat and salt anomaly extended beyond $R$ (Fig. 2). The radius of the convected area in the Labrador Sea $r_{\mathrm{LS}}$ is assumed to be $300 \mathrm{~km}$ (Lilly et al. 2003). Mean eddy profiles for the potential temperature $\theta_{e}$ and salinity $S_{e}$ are derived by horizontally averaging $\theta$ and $S$ values observed within $r_{e}$ of the eddy center. The horizontal averaging assumes that the eddy is radially symmetric. The freshwater $\Delta F$ and heat $\Delta H$ contributions per unit area for a restratifying layer of depth $D\left[D_{r}\right.$ in Hátún et al. (2007)] as given by Hátún et al. (2007) are

$$
\begin{gathered}
\Delta F=\frac{\left(S_{\mathrm{LSW}}-S_{e}\right)}{S_{\mathrm{LSW}}}\left(\frac{r_{e}}{r_{\mathrm{LS}}}\right)^{2} D \text { and } \\
\Delta H=\left(\theta_{e}-\theta_{\mathrm{LSW}}\right) \rho_{0} c_{p}\left(\frac{r_{e}}{r_{\mathrm{LS}}}\right)^{2} D,
\end{gathered}
$$

where $\rho_{0}=1027 \mathrm{~kg} \mathrm{~m}^{-3}$ is the reference density and $c_{p}=$ $4000 \mathrm{~J} \mathrm{~kg}^{-1}{ }^{\circ} \mathrm{C}^{-1}$ is the heat capacity. The reference values $\theta_{\mathrm{LSW}}$ and $S_{\mathrm{LSW}}$ are the characteristic properties of the recently ventilated $\mathrm{LSW}$, which are $3.45^{\circ} \mathrm{C}$ and 34.845, respectively, for 2005 (Hátún et al. 2007). These values are not unlike those of the mixed layers observed south of Cape Farewell in the winter of 2008 (de Jong et al. 2012). However, the LSW formed in the central Labrador Sea in the winter of 2008 was somewhat colder and more saline $\left(\theta_{\mathrm{LSW}}=3.3^{\circ} \mathrm{C}\right.$ and $S_{\mathrm{LSW}}=34.87$; Yashayeav and Loder 2009; de Jong et al. 2012). We will use both the values of 2005 and 2008 here.

Because the eddies consist of a saline (warm) core topped by a relatively fresh (colder) near-surface layer, the heat and freshwater contributions as calculated by Hátún et al. (2007) were partitioned into the contribution of the upper ( $0-200$ or $300 \mathrm{~m}$ ) and the lower (200 or 300-1000 m) layer. In this study, we lack observations 
TABLE 3. Eddy properties. The date at which the eddy center was observed, the max (ungridded) temperature, corresponding depth of instrument, max salinity, corresponding depth of instrument, salinity observed at $100-\mathrm{m}$ depth, and the vertical displacement of $27.70 \mathrm{~kg} \mathrm{~m}^{-3}$ isopycnal.

\begin{tabular}{|c|c|c|c|c|c|c|c|}
\hline Eddy (No.) & $\begin{array}{c}\text { Date } \\
\text { (dd mmm yyyy) }\end{array}$ & $\theta_{\max }\left({ }^{\circ} \mathrm{C}\right)$ & $\begin{array}{c}\text { Instrument } \\
\text { depth }(\mathrm{m})\end{array}$ & $S_{\max }$ & $\begin{array}{l}\text { Instrument } \\
\text { depth }(\mathrm{m})\end{array}$ & $S_{100}$ & $\begin{array}{c}\sigma \text { displacement } \\
\text { (dbar) }\end{array}$ \\
\hline 1 & 16 Nov 2007 & $6.60^{\circ}$ & 100 & 35.00 & 200 & 34.86 & 117 \\
\hline 2 & 28 Nov 2007 & $6.41^{\circ}$ & 200 & 34.99 & 400 & 34.65 & 356 \\
\hline 3 & 13 Apr 2008 & $4.70^{\circ}$ & 400 & 34.95 & 750 & 34.47 & 645 \\
\hline 4 & 1 May 2008 & $4.75^{\circ}$ & 400 & 34.94 & 750 & 34.77 & 480 \\
\hline 5 & 2 Jun 2008 & $4.91^{\circ}$ & 750 & 34.98 & 750 & 34.45 & 445 \\
\hline 6 & 8 Aug 2008 & $4.84^{\circ}$ & 400 & 34.97 & 750 & 34.76 & 516 \\
\hline 7 & 21 Aug 2008 & $4.84^{\circ}$ & 400 & 34.97 & 750 & 34.80 & 486 \\
\hline 8 & 11 Oct 2008 & $5.42^{\circ}$ & 100 & 35.00 & 400 & 34.94 & 243 \\
\hline 9 & 7 Nov 2008 & $5.94^{\circ}$ & 100 & 35.00 & 200 & 34.84 & 169 \\
\hline 10 & 27 Dec 2008 & $5.94^{\circ}$ & 100 & 34.97 & 200 & 34.93 & 247 \\
\hline 11 & 1 May 2009 & $4.67^{\circ}$ & 500 & 34.95 & 750 & 34.64 & 319 \\
\hline 12 & 29 Aug 2009 & $4.91^{\circ}$ & 400 & 34.95 & 750 & 34.65 & 242 \\
\hline Mean & & $5.32^{\circ}$ & & 34.97 & & 34.73 & 355 \\
\hline
\end{tabular}

from the upper $100 \mathrm{~m}$, which prevents us from estimating the contributions from the near-surface layer. The heat and freshwater contributions from the 200-1000-m layer as well as the 300-1000-m layer were calculated for each anticyclone. Values for the 200-1000-m layer are denoted in Table 4; values for the heat (freshwater) contribution of the $300-1000-\mathrm{m}$ layer are $25 \%(15 \%)$ smaller. Because the warm, saline core extends outside
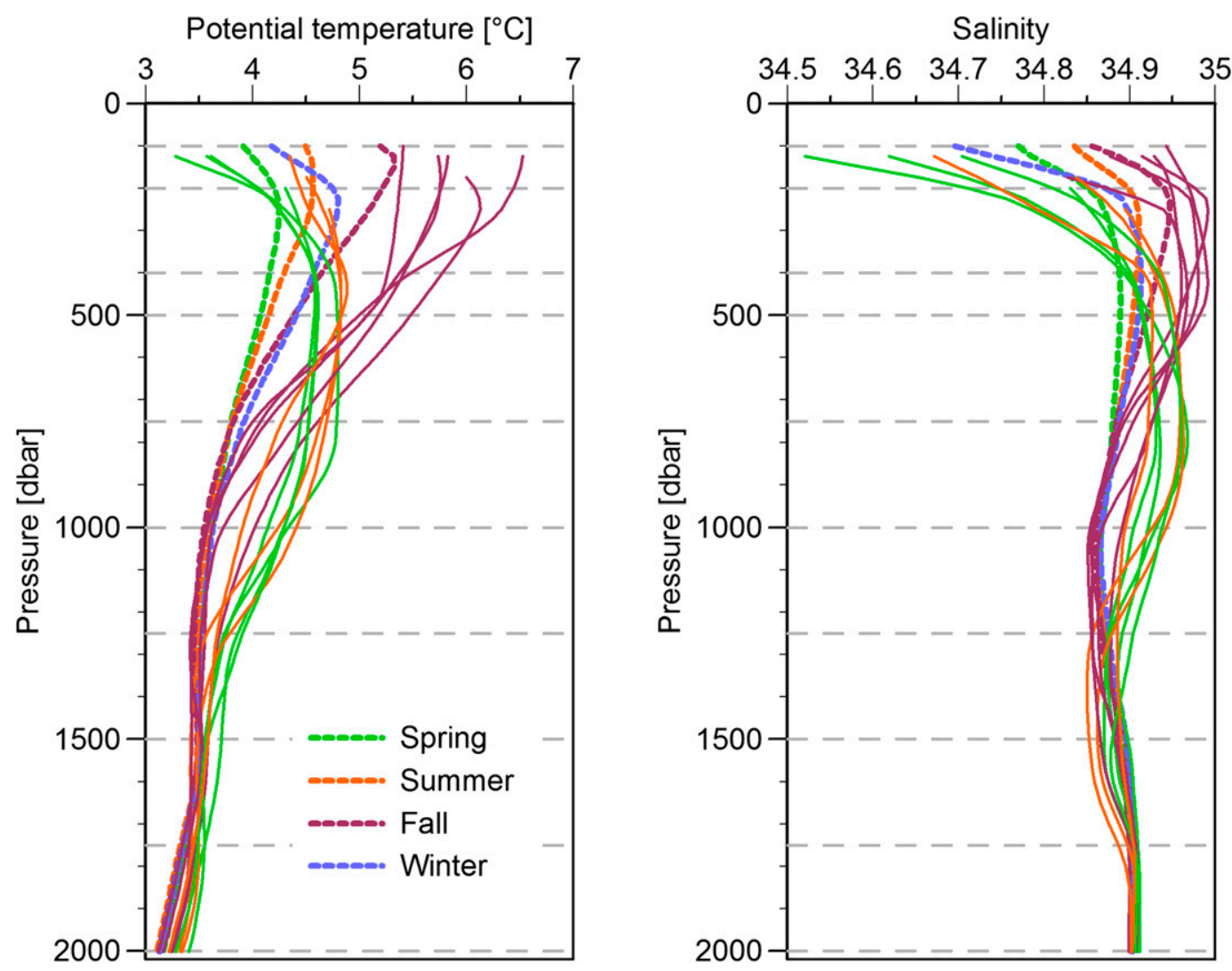

FIG. 9. Potential (left) temperature and (right) salinity profiles of the 12 eddies (solid lines) and the seasonal-mean profiles (dashed lines). These data are the 25-dbar spline-gridded profiles. The instruments depths are indicated by the horizontal dashed lines. The eddy profiles are grouped by their season of appearance: winter (JFM; no eddies), spring (AMJ; 4 eddies), summer (JAS; 3 eddies), and fall (OND; 5 eddies). Mean profiles (dashed) are derived from all profiles during the same 3 months. 
TABLE 4. Heat and freshwater contributions from the 12 warm-core anticyclones observed by the mooring compared to the contribution derived by Hátún et al. (2007). Denoted here are the radii $r_{e}$ used for the calculation of the contributions $\left(1.5 R_{0}\right)$, the radially and vertically averaged potential temperature (i.e., $\theta$ ) and salinity (i.e., $S$ ) between 200 and $1000 \mathrm{~m}$, the heat contribution (i.e., $\Delta H$ ), and the freshwater contribution (i.e., $\Delta F$ ) between 200 and $1000 \mathrm{~m}$. Values of $\Delta H$ and $\Delta F$ were also calculated using a constant for $r_{e}$ of $35 \mathrm{~km}$ (right three columns). The three eddies observed in spring are indicated with an asterisk.

\begin{tabular}{|c|c|c|c|c|c|c|c|c|}
\hline $\begin{array}{l}\text { Eddy } \\
\text { (No.) }\end{array}$ & $\theta_{200}\left({ }^{\circ} \mathrm{C}\right)$ & $S_{200}$ & $r_{e}(\mathrm{~km})$ & $\begin{array}{c}\Delta H_{200} \\
\left(\mathrm{MJ} \mathrm{m}^{-2}\right)\end{array}$ & $\Delta F_{200}(\mathrm{~cm})$ & $r_{e}(\mathrm{~km})$ & $\begin{array}{c}\Delta H_{200} \\
\left(\mathrm{MJ} \mathrm{m}^{-2}\right)\end{array}$ & $\Delta F_{200}(\mathrm{~cm})$ \\
\hline 1 & $4.41^{\circ}$ & 34.90 & 43.6 & 81 & -3.5 & 35 & 43 & -1.9 \\
\hline 2 & $4.63^{\circ}$ & 34.92 & 21.3 & 108 & -4.7 & 35 & 53 & -2.3 \\
\hline $3^{*}$ & $4.12^{\circ}$ & 34.87 & 33.1 & 68 & -2.0 & 35 & 30 & -0.9 \\
\hline $4^{*}$ & $4.13^{\circ}$ & 34.88 & 16.8 & 20 & -0.8 & 35 & 31 & -1.2 \\
\hline 5 & $4.42^{\circ}$ & 34.91 & 23.9 & 37 & -1.7 & 35 & 44 & -2.0 \\
\hline 6 & $4.48^{\circ}$ & 34.92 & 16.4 & 10 & -0.5 & 35 & 46 & -2.4 \\
\hline 7 & $4.33^{\circ}$ & 34.91 & 12.4 & 29 & -1.5 & 35 & 40 & -2.0 \\
\hline 8 & $4.34^{\circ}$ & 34.92 & 29.6 & 30 & -1.7 & 35 & 40 & -2.3 \\
\hline 9 & $4.57^{\circ}$ & 34.93 & 21.8 & 16 & -0.8 & 35 & 51 & -2.7 \\
\hline 10 & $4.55^{\circ}$ & 34.92 & 17.8 & 12 & -0.6 & 35 & 50 & -2.4 \\
\hline $11^{*}$ & $4.25^{\circ}$ & 34.91 & 12.3 & 12 & -0.7 & 35 & 36 & -2.1 \\
\hline 12 & $4.38^{\circ}$ & 34.92 & 24.7 & 53 & -3.1 & 35 & 42 & -2.5 \\
\hline Mean & $4.38^{\circ} \pm 0.16^{\circ}$ & $34.91 \pm 0.02$ & $22.8 \pm 9.1$ & $39 \pm 31$ & $-1.8 \pm 1.3$ & 35 & $42 \pm 7$ & $-2.1 \pm 0.5$ \\
\hline Hátún & $4.41^{\circ}$ & 34.88 & 35 & 43 & -1.0 & 35 & 43 & -1.0 \\
\hline
\end{tabular}

of the velocity maximum, the contributions represent the heat and freshwater contained within the radius $r_{e}=$ $1.5 R_{0}$, similar to the limit set by Hátún et al. (2007).

The values in Table 4 allow for a comparison of the structure of the eddy observed in 2005 and those observed by the mooring between September 2007 and September 2009. Because of the large uncertainties in the eddy radii, we first look at the heat contribution as a function of seasonal stratification [Fig. 10 (top)]. For this purpose we have divided the upper $1000 \mathrm{~m}$ of the water column into 3 layers of $300 \mathrm{~m}$. The upper layer extends between 100 and $400 \mathrm{~m}$, the midlayer extends between 400 and $700 \mathrm{~m}$, and the lower layer extends between 700 and $1000 \mathrm{~m}$. The contribution of each eddy and layer assumes a constant $r_{e}$ of $35 \mathrm{~km}$. Clearly the upper layer is largely responsible for the seasonal variability, with low (high) heat (freshwater) contributions in spring and early summer increasing (decreasing) toward fall. The midlayer contributes about one-third of the total heat, with a variability of about an order of magnitude smaller than that of the upper layer. The lower layer adds about one-fifth of the heat. Its variability is similar in magnitude as that of the midlayer, but is $180^{\circ}$ out of phase. While the fall anticyclones contain a lot of the heat in the upper layer, their warm anomaly does not reach as deep as the spring anomalies (Fig. 9).

The freshwater contribution shows similar division between the three layers. The upper layer can either have a positive or negative contribution depending on the presence of a thick freshwater cap. Hátún et al. (2007) found a rather small heat contribution and a larger positive freshwater contribution for the upper layer of their anticyclone. Because this anticyclone was observed in March, this fits the seasonal cycle seen in these two-year-long observations. Using the colder, more saline LSW from 2008 as a reference results in $17 \%$ larger heat contributions and $40 \%$ smaller freshwater contributions. This would make these eddies a bigger source of heat relative to the Hátún et al. (2007) eddy, but more similar with respect to the deep freshwater contribution.

The inclusion of varying radius estimates strongly increases the range of heat and freshwater contributions [Fig. 10 (bottom)]. This strongly reduces the influence of the seasonal cycle in core properties. The large spread in radii leads to a large range in heat and freshwater content, with the standard deviation over the set of 12 anticyclones nearly as big as the mean $\left(\Delta H_{200}=39 \pm\right.$ $31 \mathrm{MJ} \mathrm{m}^{-2}$ and $\Delta F_{200}=-1.8 \pm 1.3 \mathrm{~cm}$; Table 4$)$. The volume of the eddies, and thereby $\Delta H$ and $\Delta F$, depends on the radius, resulting in high correlations between $R_{0}$ and the heat and freshwater contributions (correlations of 0.9 and 0.7 , respectively). The heat and freshwater contribution are also calculated for the lower and upper bound of $R_{0}$. These values, illustrated by the bars in the bottom panels of Fig. 10, are considered to be the absolute boundaries of our estimates. They illustrate the necessity for reliable radius estimates.

\section{Discussion}

Between 25 September 2007 and 28 September 2009, 12 warm-core anticyclone events resembling Irminger rings were observed at the location of the IRINGS 

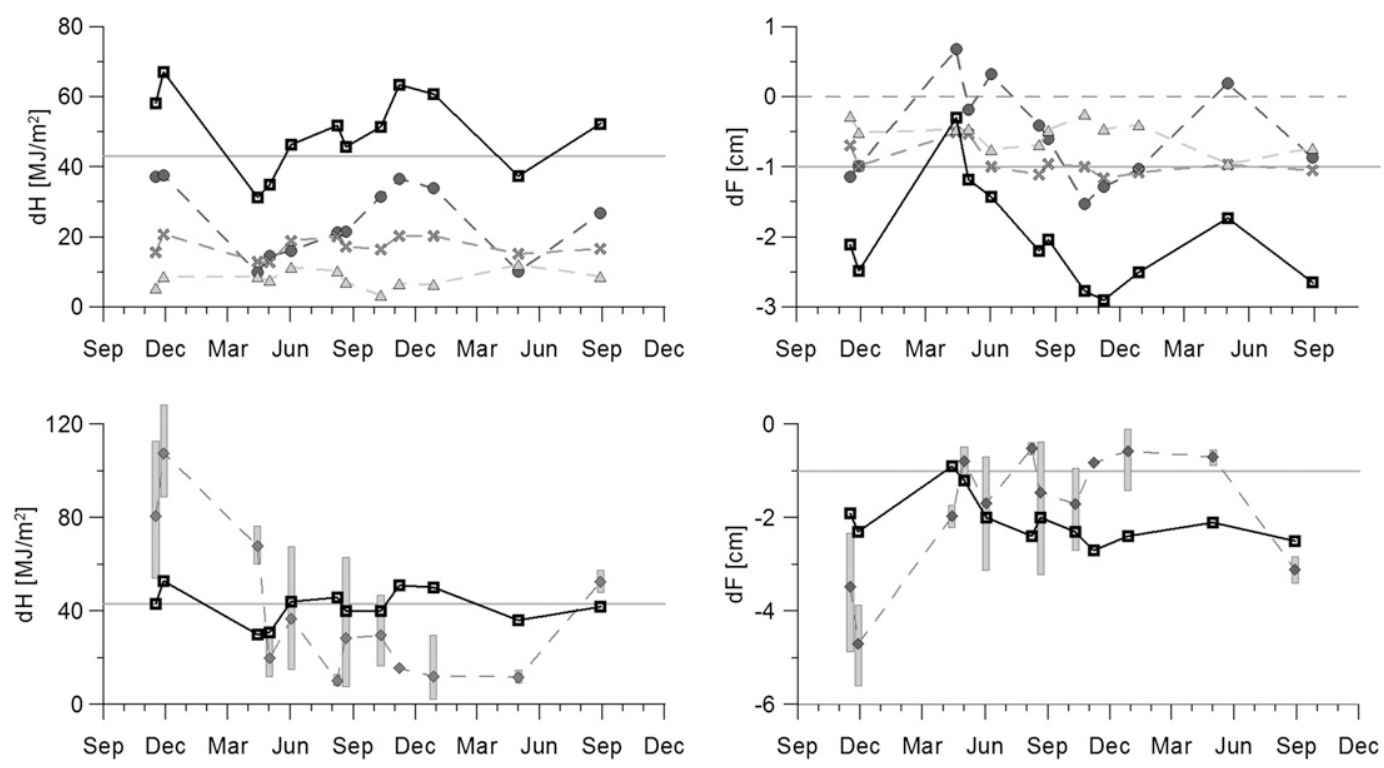

FIG. 10. (top) Seasonal cycle of the heat (left) and freshwater (right) contribution per layer. To investigate the effect of the seasonal stratification on the heat and freshwater contribution was calculated for each anticyclone using $r_{e}=35 \mathrm{~km}$ for separate layers. The upper layer (dark gray, dots) extends between 100 and $400 \mathrm{~m}$. The midlayer (medium gray, crosses) extends between 400 and $700 \mathrm{~m}$. The lower layer (light gray, triangles) extends between 700 and $1000 \mathrm{~m}$. The total is shown in black with squares. (bottom) The 200-1000-m heat (left) and freshwater (right) contribution for a fixed $r_{e}$ of $35 \mathrm{~km}$ (black, squares) vs contributions based on the estimated radii $R_{0}$ (dashed gray, diamonds). The gray bars indicate the range between the contribution based on the lower and upper bound of $R_{0}$.

moorings, southwest of the maximum in EKE near the west Greenland coast. We judge 11 of these events to be distinct eddies, based on their characteristics summarized in Tables 2 and 3.

A comparison between the mooring data and SLA gridded maps showed that tracking anticyclones in the Labrador Sea is not straightforward for two reasons. First, the eddies have to be sampled by the along-track altimetry observations. We found one instance, out of 12 , in which it was undisputable that a positive anomaly in the along-track SLA data was identical to an anticyclone observed at the mooring. Second, the dynamic height anomalies associated with the eddies are small in amplitude and scale, thus most of their signal is removed from the heavily smoothed, gridded maps. Subjective tracking of SLA anomalies was done by Furey et al. (2013a, their Fig. 1), but resulted only in one or two reliable tracks annually. Likely, these tracks were associated with some of the larger eddies.

The radii were estimated using the dynamic height anomalies and the velocities observed at the mooring assuming a geostrophic balance. The apparent radii varied between 11 and $35 \mathrm{~km}$. These estimates of the radii could certainly be improved if more spatial data had been available. Nevertheless, they suggest that either the IRs have a larger size range than previously estimated or that the observed warm-core eddies were a mix of smaller BCEs and larger IRs. BCEs are shed by the boundary current all around the basin and thus may also be observed near the location of topographic instability, where their core characteristics will be similar to IRs. However, earlier observational studies targeted anticyclones using altimetry, and thus selectively observed the larger IRs.

The 2-year time series showed a large seasonal cycle in the eddy core properties that has not been described before. Minima in temperature and salinity are observed in late spring and maxima are observed in late fall. The range of the seasonal cycle in potential temperature is about $1.9^{\circ} \mathrm{C}$. The range of middepth salinity variations is 0.07 , while the range of near-surface salinity variations is nearly an order of magnitude larger at 0.49 . This large variability is caused by the seasonal presence of a fresh near-surface layer. The seasonal cycle in eddy properties agrees well with the seasonal cycle of the boundary current described by Rykova (2010). She observed the highest (lowest) boundary current temperatures and salinities at middepth in fall (spring). The year-to-year changes in boundary current properties, observed during the years around the mooring deployment, are much smaller. Hydrographic data from the cross section of the AR7W section and the WGC/IC system were obtained for May 2006, 2007, and 2008, August 2008, and May 2009 
and 2010. May surveys were performed by the Bedford Institute of Oceanography (BIO), Dartmouth, Canada, while the August 2008 survey was performed by the National Oceanography Centre (NOC), Southampton, United Kingdom. Rykova (2010) used two definitions for the Irminger Current core properties (Fig. 11): an inshore IC box $65-85-\mathrm{km}$ offshore and between 300 - and 700-m depth and a full IC box extending from the coast to the 3000-m isobath horizontally and between 200 - and 1000-m depth vertically. Maximum $\theta$ and $S$ in both boxes of the Irminger Current are shown in Fig. 12, as well as the maximum $\theta$ and $S$ observed in the eddies. The seasonal change in stratification of the upper layers stands out in Fig. 11. The interannual change in properties during the mooring deployment is much smaller. The temperature decreased somewhat, possibly because of strong cooling and convective mixing in the Irminger Sea in the winter of 2008 (de Jong et al. 2012). The salinity of the Irminger Current shows an overall increasing trend over the 5 years, which fits with the ongoing increase in salinity in the Labrador and Irminger Seas during the last decade (van Aken et al. 2011). The interannual salinity trend may also explain why the cores of the eddies observed by the mooring were more saline than the eddies observed in 2005 by Hátún et al. (2007).

The change in near-surface salinities seems to be more complicated. Although this time series lacks observations from the upper $100 \mathrm{~m}$, some trends are visible. Fresh near-surface layers are mostly seen early in the year and disappear toward fall (Fig. 9). In fall, the density stratification near the surface is maintained by higher temperatures, rather than by lower salinities. Irminger rings observed at the Bravo mooring also lacked a fresh cap (Lilly et al. 2003), but there it was suggested that the fresh layer had been mixed away in winter. No mixed layers were seen in the 12 eddy events described in this study. The presence of freshwater in the nearsurface layer may be related to the seasonal cycle of freshwater in the WGC caused by meltwater from Greenland and falls outside the scope of this study.

The implications of the observed seasonal cycle for the heat and freshwater budget of the Labrador Sea are twofold. Hátún et al. (2007) estimated that the lateral freshwater flux estimated by Straneo (2006) could be supplied by 25 Irminger rings and that the annual lowerlayer heat convergence required 21 IRs. These estimates were based on an IR observed in early spring with a deep freshwater cap and a radius of $21 \mathrm{~km}$. The seasonal cycle we observed indicates that the freshwater transport by anticyclones in summer and fall is significantly smaller and possibly other sources of freshwater are needed to close the budget. Also, the strong seasonal cycle in temperature stratification suggests that the 2005 eddy was not

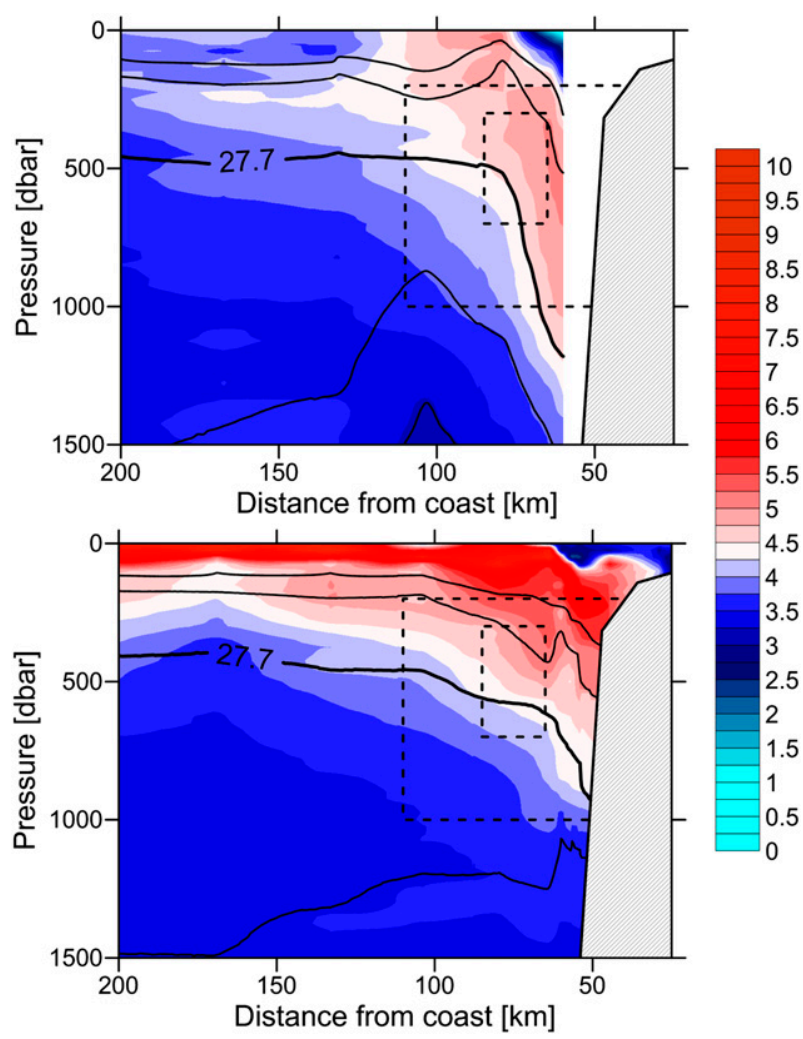

FIG. 11. Temperature distribution on the AR7W section across the Irminger Current in (top) May 2008 and (bottom) August 2008. The two panels illustrate the seasonal cycle seen in the Irminger Current, with the warm (saline) core moving upward toward the end of summer and the cold near-surface layer disappearing. Isopycnals are drawn every $0.05 \mathrm{~kg} \mathrm{~m}^{-3}$ with the $27.7 \mathrm{~kg} \mathrm{~m}^{-3}$ indicated. The inshore box and full box as defined by Rykova (2010) for which values were derived for Fig. 12 are drawn with dashed lines.

representative for the mean heat transport. The heat contribution of the upper layer will be larger in fall when the cold fresh upper layer is replaced by a warm layer. Notably, the density of the upper layer of the warmer fall eddies is lower than that of the fresher spring eddies. This suggests that while the restratification of the interior starts in spring, the density contrast between the interior and the boundary is (partly) conserved, facilitating the year-round continuation of restratification observed by Straneo (2006).

The exact heat and freshwater contributions of the warm-core anticyclones to the restratification of the Labrador Sea remain elusive. Although our radius estimates are not perfect, they suggest that a large range of sizes of warm-core eddies is probable. Eddy censuses based on altimetry (Lilly et al. 2003) or hydrographic sections (Rykova et al. 2009) likely underestimated the numbers of (small) eddies present in the Labrador Sea. The seasonal cycle observed in the core properties 

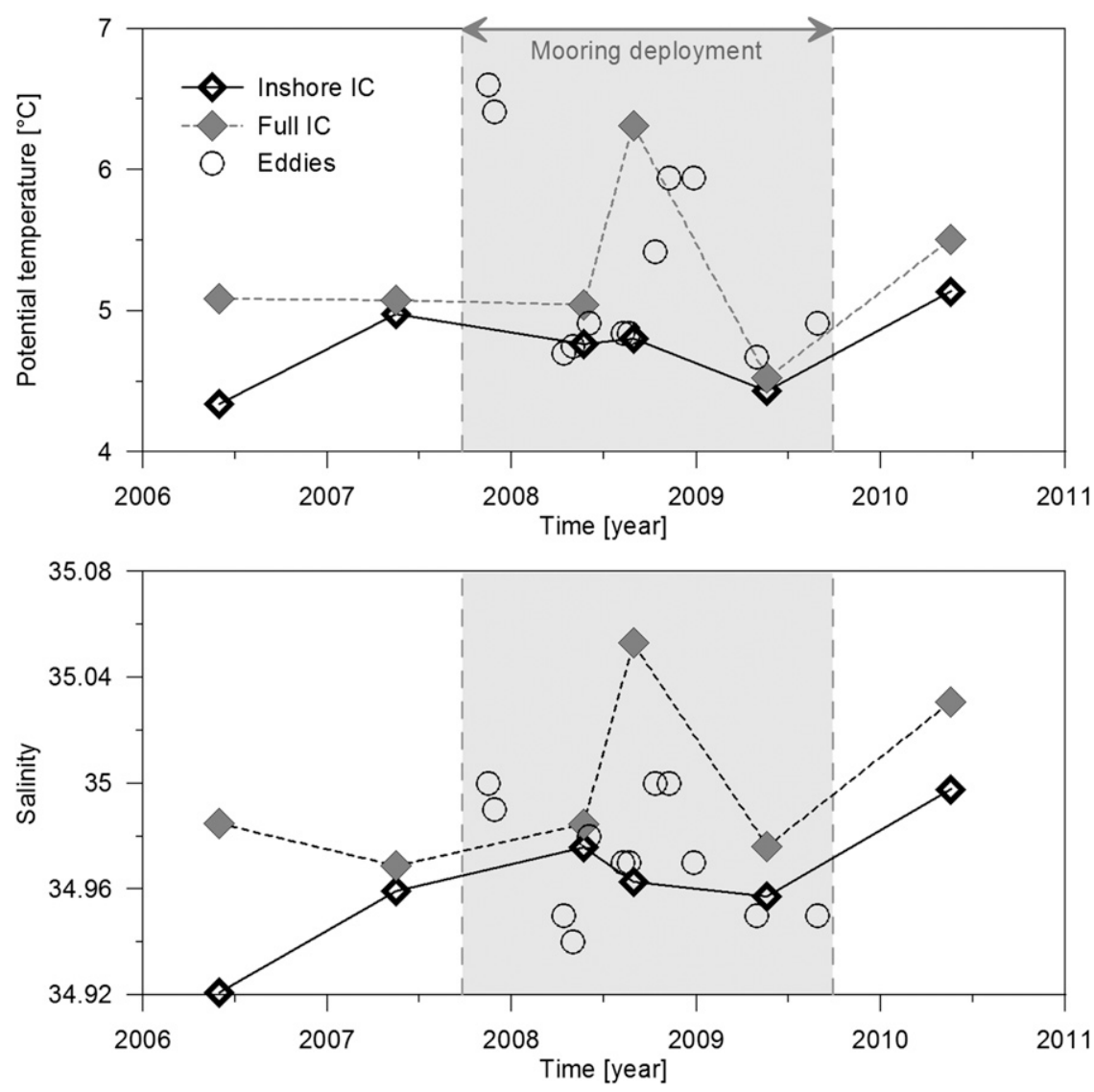

FIG. 12. Irminger Current properties observed in the AR7W section in May 2006, 2007, and 2008, August 2008, and May 2009 and 2010 and core eddy properties. Values were determined for the two definitions of the Irminger Current core used by Rykova (2010), the inshore box between 65 - and $85-\mathrm{km}$ offshore and 300- and 700-m depth, and the full box between the coast, the 3000-m isobath, and 200- and 1000-m depth. The boxes are shown in Fig. 11. (top) The max potential temperature in the full (gray, dashed) and inshore box (black, solid) of the Irminger Current as well as the max potential temperatures observed in the Irminger rings (circles). (bottom) The max salinity in the full and inshore box of the Irminger Current as well as the max observed in the Irminger rings.

indicates that the heat and salt content is not only dependent on the radius, but also on the season of formation. Finally, evidence suggests that not all anticyclones (observed in this study) make it to the interior Labrador Sea. Several anticyclones as well as APEX floats deployed by the mooring moved in a direction associated with a cyclonic recirculation off the west coast of Greenland (Lavender et al. 2000; Spall and Pickart 2003; Hall et al. 2013), away from the central Labrador Sea and back toward the boundary current. More needs to be known about how and where these warm-core anticyclones release their heat and salt content. While this last statement is generally true for the entire ocean, it is especially important for the Labrador Sea where eddy fluxes are an important process in the deep water formation cycle. A proper description of eddy fluxes and their variability based on observations will help improve their parameterization in coupled climate models. This will refine our understanding of deep water formation and associated changes in the Atlantic meridional overturning circulation in future climates.

Acknowledgments. This work was supported by the U.S. National Science Foundation and the Postdoctoral Scholar Program at the Woods Hole Oceanographic Institution, with funding provided by the Devonshire Foundation. The authors gratefully acknowledge the captain and crew of the R/V Knorr for their assistance in the successful deployment and recovery of the IR mooring. The technical expertise of W. Ostrom, J. Valdes, and J. Kemp at sea was critical to the success of the mooring 
operations. S. Worrilow, B. Hogue, and R. Trask are also acknowledged for the preparation of the mooring and instrumentation. We kindly thank Jonathan Lilly for useful discussions and Ross Hendry and Igor Yashayaev (BIO) and Sheldon Bacon and Penny Holliday (NOC) for their efforts to monitor the AR7W section. The altimeter products were produced by Segment Sol multimissions d'ALTimétrie, d'Orbitographie et de localisation précise (SSALTO)/Data Unification and Altimeter Combination System (DUACS) and distributed by AVISO, with support from Centre National d'Etudes Spatiales (CNES; http://www.aviso.oceanobs.com/duacs/). The integrated multimission ocean altimeter data were obtained from the Physical Oceanography Distributed Active Archive Center (PO.DAAC) at the National Aeronautics and Space Administration (NASA) Jet Propulsion Laboratory in Pasadena, California (http://podaac. jpl.nasa.gov).

\section{REFERENCES}

Bracco, A., and J. Pedlosky, 2003: Vortex generation by topography in locally unstable baroclinic flows. J. Phys. Oceanogr., 33, 207-219.

,-- , and R. S. Pickart, 2008: Eddy formation near the west coast of Greenland. J. Phys. Oceanogr., 38, 1992-2002.

Brandt, P., F. A. Schott, A. Funk, and C. S. Martins, 2004: Seasonal to interannual variability of the eddy field in the Labrador Sea from satellite altimetry. J. Geophys. Res., 109, C02028, doi:10.1029/2002JC001551.

Chanut, J., B. Barnier, W. Large, L. Debreu, T. Penduff, J. M. Molines, and P. Mathiot, 2008: Mesoscale eddies in the Labrador Sea and their contribution to convection and re-stratification. J. Phys. Oceanogr., 38, 1617-1643.

Chelton, B. D., M. G. Schlax, and R. M. Samelson, 2011: Global observations of nonlinear mesoscale eddies. Prog. Oceanogr., 91, 167-216, doi:10.1016/j.pocean.2011.01.002.

Cuny, J., P. Rhines, S. Niiler, and S. Bacon, 2002: Labrador Sea boundary currents and the fate of the Irminger Sea Water. J. Phys. Oceanogr., 32, 627-647.

de Jong, M. F., H. M. van Aken, K. Våge, and R. S. Pickart, 2012: Convective mixing in the central Irminger Sea: 2002-2010. Deep-Sea Res. I, 63, 36-51, doi:10.1016/j.dsr.2012.01.003.

Eden, C., and C. Böning, 2002: Sources of eddy kinetic energy in the Labrador Sea. J. Phys. Oceanogr., 32, 3346-3363.

Fratantoni, D. M., 2014: Environmentally-adaptive deployment of Lagrangian instrumentation using a submerged autonomous launch platform (SALP). Mar. Technol. Soc. J., 48 (1).

Furey, H. H., M. F. de Jong, J. Valdes, and A. S. Bower, 2013a: Eddy seeding in the Labrador Sea: A submerged autonomous launch platform application. J. Atmos. Oceanic Technol., 30, 2611-2629.

, T. McKee, M. F. de Jong, P. E. Robbins, and A. S. Bower, 2013b: Impact of Irminger rings on deep convection in the Labrador Sea: Mooring instrument, CTD, and APEX data report September 2007-September 2009. Woods Hole Oceanographic Institution Tech. Rep. WHOI-2013-05, 103 pp.

Gelderloos, R., C. A. Katsman, and S. S. Drijfhout, 2011: Assessing the role of three eddy types in restratifying the
Labrador Sea after deep convection. J. Phys. Oceanogr., 41, 2102-2119.

Hall, M. M., D. J. Torres, and I. Yashayaev, 2013: Absolute velocity along the AR7W section in the Labrador Sea. Deep-Sea Res. I, 72, 72-87, doi:10.1016/j.dsr.2012.11.005.

Hátún, H., C. C. Eriksen, and P. B. Rhines, 2007: Buoyant eddies entering the Labrador Sea observed with gliders and altimetry. J. Phys. Oceanogr., 37, 2838-2854.

Holliday, N. P., A. Meyer, S. Bacon, S. Alderson, and B. A. deCuevas, 2007: The retroflection of part of the East Greenland Current at Cape Farewell. Geophys. Res. Lett., 34, L07609, doi:10.1029/2006GL029085.

— S. Bacon, J. Allen, and E. L. McDonagh, 2009: Circulation and transport in the western boundary currents at Cape Farewell, Greenland. J. Phys. Oceanogr., 39, 1854-1870.

Jones, H., and J. Marshall, 1993: Convection with rotation in a neutral ocean: A study of open-ocean deep convection. J. Phys. Oceanogr., 23, 1009-1039.

$\longrightarrow$, and —, 1997: Restratification after deep convection. J. Phys. Oceanogr., 27, 2276-2286.

Katsman, C. A., M. A. Spall, and R. S. Pickart, 2004: Boundary current eddies and their role in the restratification of the Labrador Sea. J. Phys. Oceanogr., 34, 1967-1983.

Lavender, K. L., R. E. Davis, and W. B. Owens, 2000: Middepth recirculation observed in the interior Labrador and Irminger Seas by direct velocity measurements. Nature, 407, 66-69.

Lazier, J. R. N., 1973: The renewal of Labrador Sea Water. DeepSea Res., 20, 341-353.

, R. Hendry, R. A. Clarke, I. Yashayaev, and P. B. Rhines, 2002: Convection and restratification in the Labrador Sea, 1990-2000. Deep-Sea Res. I, 49, 1819-1835, doi:10.1016/ S0967-0637(02)00064-X.

Lilly, J. M., and P. B. Rhines, 2002: Coherent eddies in the Labrador Sea observed from a mooring. J. Phys. Oceanogr., 32, $585-598$.

,-- M. Visbeck, R. E. Davis, J. R. N. Lazier, F. Schott, and D. Farmer, 1999: Observing deep convection in the Labrador Sea during winter 1994-95. J. Phys. Oceanogr., 29, 2065-2098.

- — - R. Schott, K. Lavender, J. Lazier, U. Send, and E. D'Asaro, 2003: Observations of the Labrador Sea eddy field. Prog. Oceanogr., 59, 75-176.

Marshall, J., and F. Schott, 1999: Open-ocean convection: Observations, theory, and models. Rev. Geophys., 37, 1-64.

_- and Coauthors, 1998: The Labrador Sea deep convection experiment. Bull. Amer. Meteor. Soc., 79, 2033-2058.

Pickart, R. S., D. J. Torres, and R. A. Clarke, 2002: Hydrography of the Labrador Sea during active convection. J. Phys. Oceanogr., 32, 428-457.

Prater, M. D., 2002: Eddies in the Labrador Sea as observed by profiling RAFOS floats and remote sensing. J. Phys. Oceanogr., 32, 411-427.

Rykova, T., 2010: The seasonal and interannual variability of the West Greenland Current system in the Labrador Sea. Ph.D thesis, Massachusetts Institute of Technology/Woods Hole Oceanographic Institute Joint Program, $159 \mathrm{pp}$.

_ , F. Straneo, J. M. Lilly, and I. Yashayaev, 2009: Irminger Current anticyclones in the Labrador Sea observed in the hydrographic record, 1990-2004. J. Mar. Res., 67, 361-384.

Spall, M. A., 2004: Boundary currents and water mass transformation in marginal seas. J. Phys. Oceanogr., 34, 11971213. 
— , and R. S. Pickart, 2003: Wind-driven recirculations and exchange in the Labrador and Irminger Seas. J. Phys. Oceanogr., 33, 1829-1845.

Straneo, F., 2006: Heat and freshwater transport through the central Labrador Sea. J. Phys. Oceanogr., 36, 606-628.

Talley, L. D., and M. S. McCartney, 1982: The distribution and circulation of Labrador Sea Water. J. Phys. Oceanogr., 12, 1189-1205.

van Aken, H. M., M. F. de Jong, and I. Yashayaev, 2011: Decadal and multi-decadal variability of Labrador Sea water in the north-western North Atlantic Ocean derived from tracer distributions: Heat budget, ventilation, and advection. Deep-Sea Res. I, 58, 505-523.
Visbeck, M. J., J. Marshall, and H. Jones, 1996: Dynamics of isolated convective regions in the ocean. J. Phys. Oceanogr., 26, $1721-1734$.

Wolfe, C. L., and C. Cenedese, 2006: Laboratory experiments on eddy generation by a buoyant coastal current flowing over variable bathymetry. J. Phys. Oceanogr., 36, 395-411.

Yashayaev, I., and J. W. Loder, 2009: Enhanced production of Labrador Sea Water in 2008. Geophys. Res. Lett., 36, L01606, doi:10.1029/2008GL036162.

- M. Bersch, and H. M. van Aken, 2007: Spreading of the Labrador Sea Water to the Irminger and Iceland Basins. Geophys. Res. Lett., 34, L10602, doi:10.1029/2006GL028999. 